$$
\angle A-S \cup B--96-106
$$

INVESTIGATION OF HIGH PURITY BERYLLIUM FOR THE INTERNATIONAL THERMONUCLEAR EXPERIMENTAL REACTOR (ITER)

\title{
TASK 002
}

DETERMINATION OF MICROSTRUCTURAL CHARACTERISTICS AND CREATION OF TECHNICAL PROJECT FOR IRRADIATION EXPERIMENTS, CLEARING BEHAVIOR OF BERYLLIUM MATERIALS UNDER CONDITIONS, CLOSE TO THERMONUCLEAR REACTOR.

\section{FINAL REPORT}

PRINCIPAL INVESTIGATOR: S.P.Vagin, Ph.D.

DISTRIBUTION OF THIS DOCUMENT IS UNLIMITED

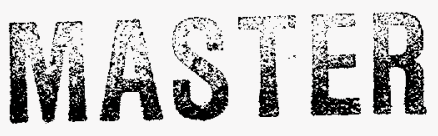




\section{DISCLAIMER}

This report was prepared as an account of work sponsored by an agency of the United States Government. Neither the United States Government nor any agency thereof, nor any of their employees, make any warranty, express or implied, or assumes any legal liability or responsibility for the accuracy, completeness, or usefulness of any information, apparatus, product, or process disclosed, or represents that its use would not infringe privately owned rights. Reference herein to any specific commercial product, process, or service by trade name, trademark, manufacturer, or otherwise does not necessarily constitute or imply its endorsement, recommendation, or favoring by the United States Government or any agency thereof. The views and opinions of authors expressed herein do not necessarily state or reflect those of the United States Government or any agency thereof. 


\section{DISCLAMMER}

Portions of this document may be illegible in electronic image products. Images are produced from the best available original document. 


\begin{abstract}
The report includes a description of experimental abilities of Solid Structure Research Laboratory of IAE NNC RK, a results of microstructural characterization of A-4 grade polycrystal Beryllium produced at the Ulba metal plant and a technical project.for irradiation experiments. Technical project contains a detailed description of five proposed experiments, clearing behavior of Beryllium materials under the influence of irradiation, temperature, helium and hydrogen accumulation. Complex irradiation jobs, microstructural investigations and mechanical tests are planned in the framework of these experiments.
\end{abstract}


LIST OF PARTICIPANTS

B.D.Utkelbayev

P.V.Chakrov

A.A.Loktionov

V.P.Poltavtseva

N.A.Pjatiletova

N.K.Kospanov 


\section{CONTENTS}

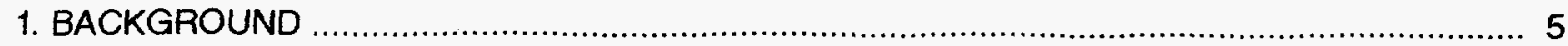

2. INFORMATION ABOUT SOLID STRUCTURE RESEARCH LABORATORY (SSRL) ..................6 6

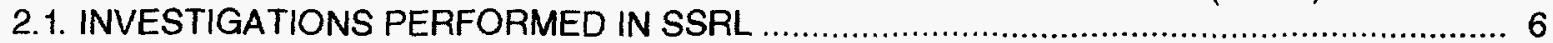

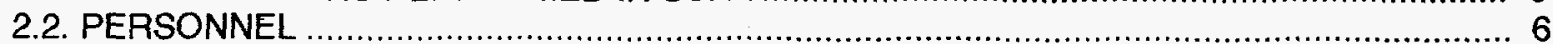

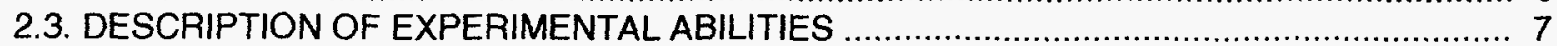

2.3.1. ISOCHRONOUS CYCLOTRON U-150 M ......................................................... 7

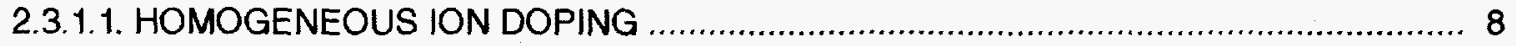

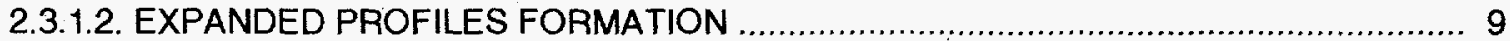

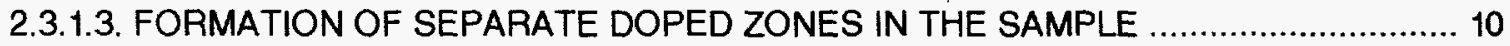

2.3.1.4. FORMATION OF PERIODICALLY ARRANGED REGIONS OF IMPLANTATION ........ 11

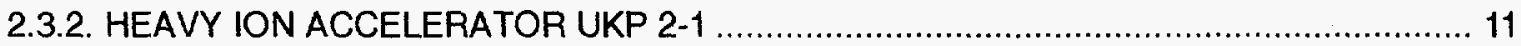

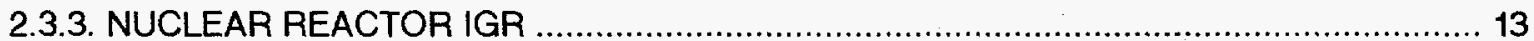

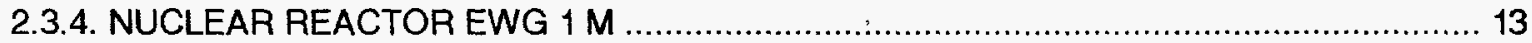

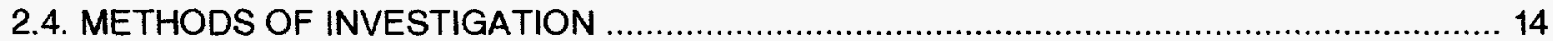

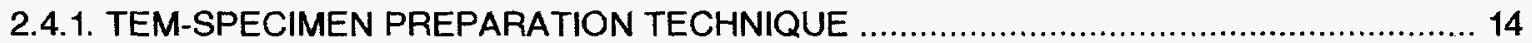

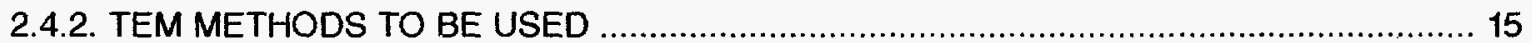

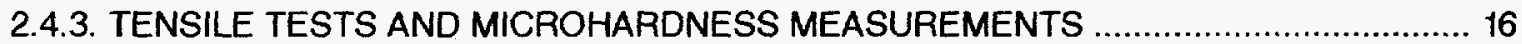

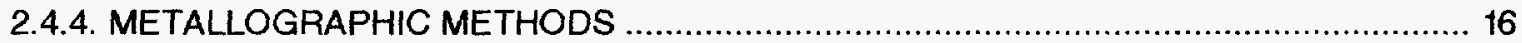

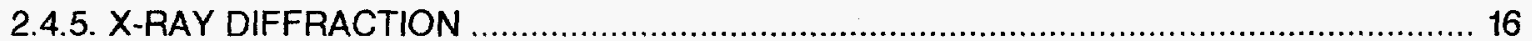

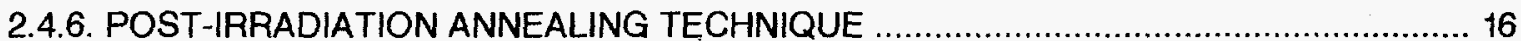

3. MICROSTRUCTURAL CHARACTERIZATION OF POLYCRYSTAL BERYLLIUM MATERIAL.... 17

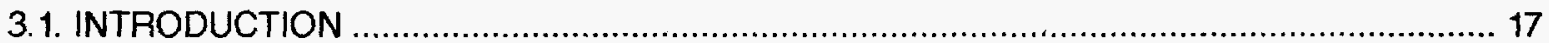

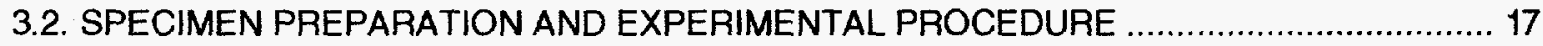

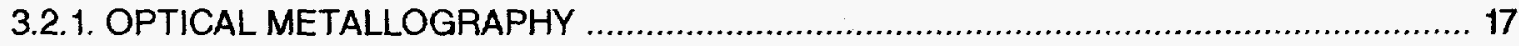

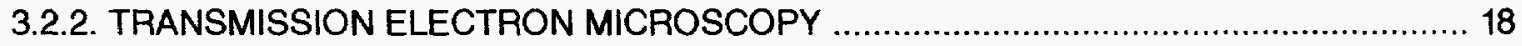

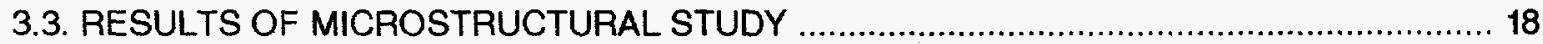

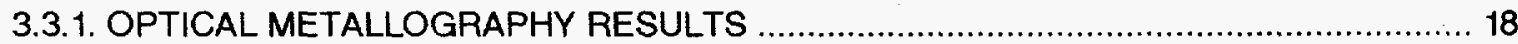

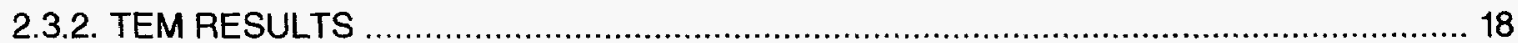

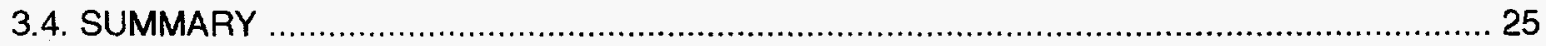

4. TASK FORMULATION FOR THE DEVELOPMENT OF THE PROJECT ON THE EXPERIMENTS FOR INVESTIGATION OF BERYLLIUM MATERIALS BEHAVIOR UNDER CONDITIONS, CLOSE TO THERMO-NUCLEAR REACTOR (TNR) ............................... 25

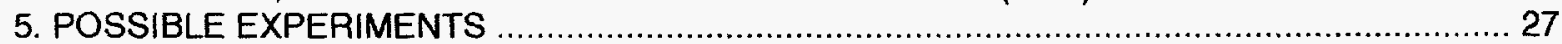

5.1. EXPERIMENT A

5.2. EXPERIMENT B

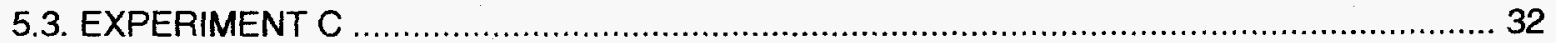

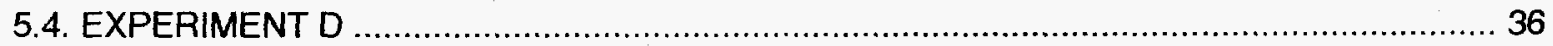

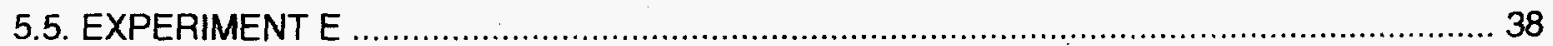

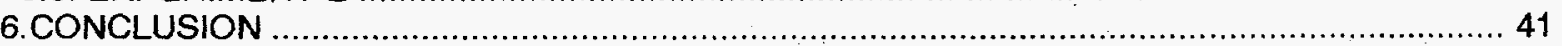

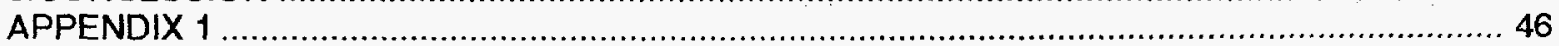

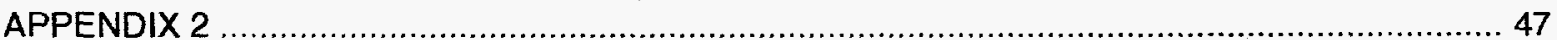

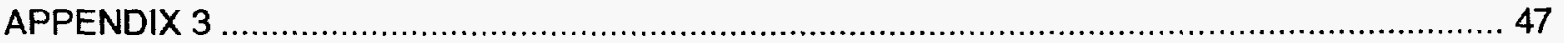

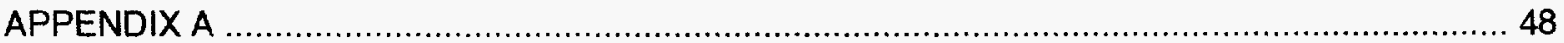

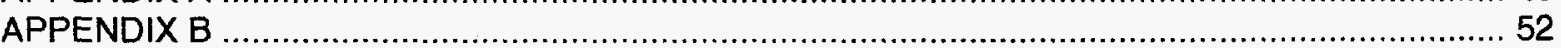

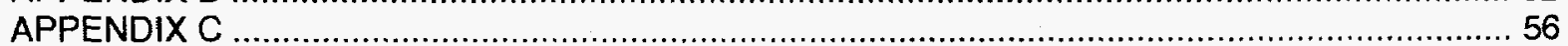

APPENDIX D

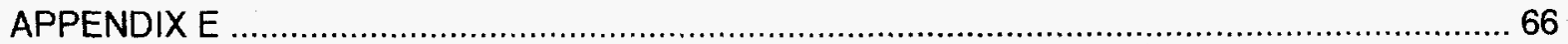




\section{BACKGROUND}

Present work is based on the agreement 5462U0015-35 dated 21 november 1994 between the Regents of the University of California and the Science Technical 'Center of Controlled Thermonuclear Fusion of the Republic of Kazahstan.

The purpose of agreement is to determine some characteristics of polycrystal beryllium material and to create technical project for reactors experiments, clearing behavior of beryllium materials under conditions, close to TNR.

According to TASK 002 of agreement it is necessary to develop technical project, including description of technical parameters and conditions of experiments, description of experimental methods, list of existing and needed equipment for the performance of experiments, price-list of each proposed experiment on the following themes: sample preparation and examination in TEM, sample irradiation it cyclotron by alpha-particles (up to $500 \mathrm{appm} \mathrm{He}$ ), and sample irradiation in tandem accelerator by protons (up to 1000 appm $\mathrm{H}$ ) with damage level about $30 \mathrm{dpa}$, plastic properties investigation of irradiated and not irradiated beryllium.

During agreement performance a possibility has arised to extend possible work relatively to the agreement conditions.

Therefore, we decided to present more complete information about our abilities and to give detail description of some possible experiments in the framework of future collaboration. Acquaintance with this possibilities could help to get clear notion about our laboratory and to choose experiments for the continuation of collaboration. 


\section{INFORMATION ABOUT SOLID STRUCTURE RESEARCH LABORATORY (SSRL)}

\subsection{INVESTIGATIONS PERFORMED IN SSRL}

Solid Structure Research Laboratory (SSRL) of the Institute of Atomic Energy, National Nuclear Center of the Republic of Kazahstan (IAE NNC RK) has been performing investigations in radiation physics of solids, including radiation effects in reactor materials, for last 20 years.

Main directions of investigations are the following:

1) Basic research on the initial radiation damage in metals under charge-particle and neutron irradiation; clarification of damage character depending on energy and mass of bombarding particles (and primary knock-on spectra); study of cascade damage [1-5].

2) Interactions between radiation defects and gas impurities (helium, hydrogen). Microstructure evolution under irradiation and during post-irradiation annealing, correlation between microstructure and physical and mechanical properties of materials [6-13].

3) Phase transformations in reactor materials (stainless steels and alloys) doped with helium [14-23]:

4) Simulation of fusion reactor radiation damage using ion accelerators, development of irradiation techniques [24-26].

\subsection{PERSONNEL.}

The project main technical staff are the members of staff of the Solid Structure Research Laboratory:

Sergei Petrovich Vagin, a cand. of phys. and math. sci., the laboratory head, a qualified specialist in the field of radiation material science and electron microscopy, the project leader.

Bekmuhamed Dzharmuhamedovich Utkelbayev, cand. of phys. and mat. sci., the deputy of the laboratory head, a qualified specialist in the field of 
radiation material science and electron microscopy, a coordinator of all experiments, a performer of structural studies.

Peter Vasilievich Chakrov, a scientific researcher, qualified specialist in the field of radiation material science, electron microscopy and electrochemical treatment of materials, a performer of TEM and SEM-studies and material irradiation at the cyclotron.

Andrei Albertovich Loktionov, a cand. of phys. and mat. sci., a senior scientific researcher, a qualified specialist in the field of radiation material science, a performer of cyclotron and reactor irradiation.

Valentina Pavlovna Poltavtseva, cand. of phys. and mat. sci., a specialist in the field of radiation material science, a performer of material mechanical tests and cyclotron irradiation.

Nigmet Kospanovich Kospanov, an engineer, a specialist in equipment, a performer of SEM studies and reactor irradiation.

Nadezhda Alexandrovna Pyatiletova, an engineer, a specialist in equipment, a performer of metallography studies and microhardness measurements.

A support staff ( 8 persons) is used in the Project: two engineers, four technicians, two laboratory assistants.

All the data concerning the personnel staff are presented in Appendix 1. The main technical staff takes part in the Project all the time.

The support staff is used for execution of definite jobs: engineers are expected to design and to adjust target and ampule devices, technicians are to prepare the target and ampule devices for irradiation and to fulfil irradiation as well, laboratory assistants are to prepare specimens for TEM and SEM studies.

\subsection{DESCRIPTION OF EXPERIMENTAL ABILITIES.}

\subsubsection{ISOCHRONOUS CYCLOTRON U-150 M.}

At the isochronous cyclotron $\mathrm{U}-150 \mathrm{M}$ (fig.2.1) the sample bulk doping by helium and/or hydrogen is fulfilled, as well as formation of various damage profiles 
through the specimen surface and depth with specially devised irradiation techniques and devices applied.

\section{Technical characteristics:}

Accelerated ion mass

Ion energy

Energy spread

Ion beam current

Number of experimental channels

1-4 amu;

$7-60 \mathrm{MeV}$;

$1 \%$;

up to $50 \mu \mathrm{A}$;

4.

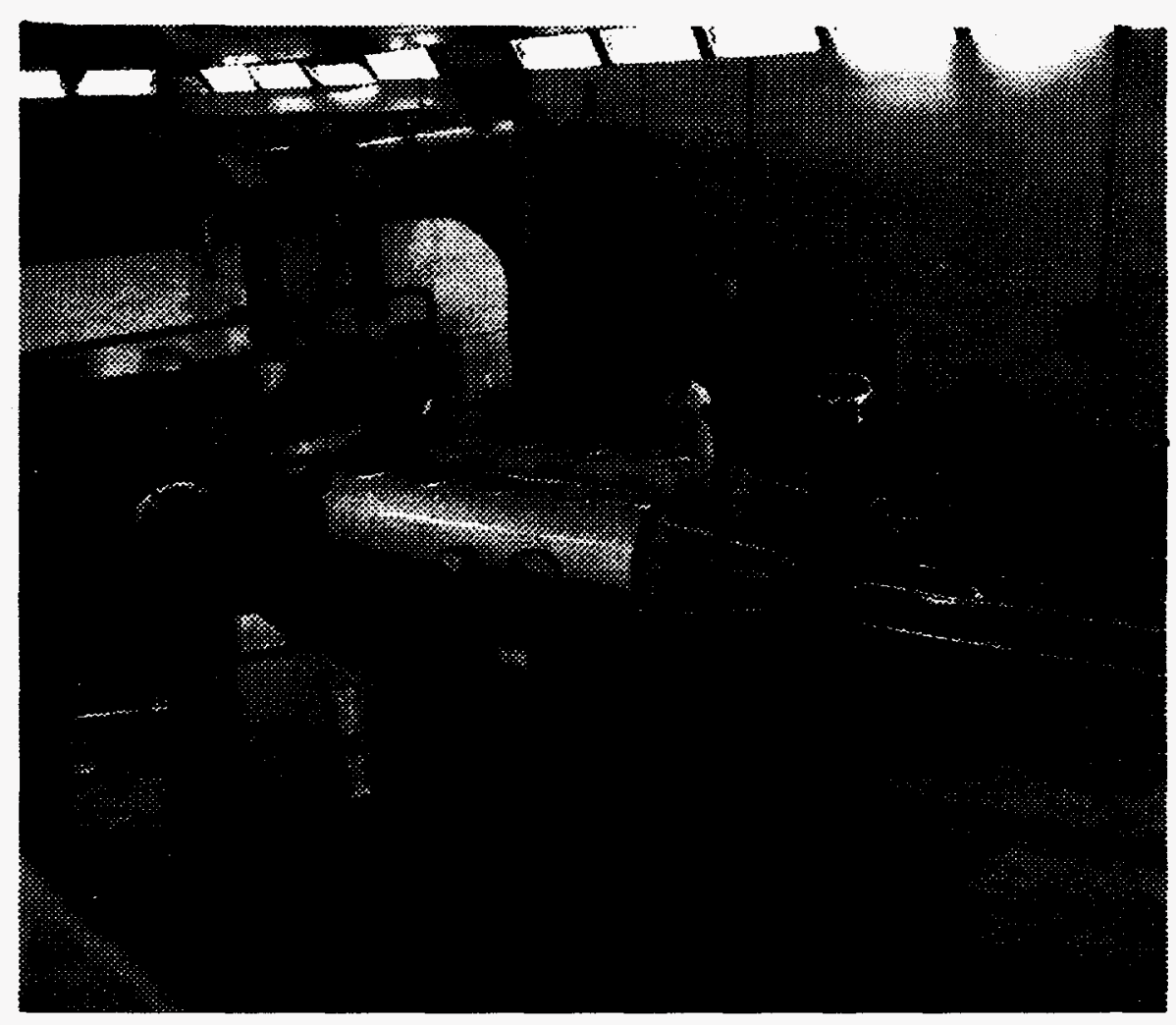

Fig.2.1. Isochronous cyclotron U-150 M.

\subsubsection{Homogeneous ion doping}

Homogeneous doping through the sample thickness is caused by moving of wedge stopping filter in front of samples, while the samples are motionless and fixed on bulk copper plate, which is heated to high temperatures by inside heater (fig.2.2).

Technical parameters of homogeneous volume doping of samples by helium and hydrogen atoms: 
Sample thickness

doped with helium . up to $1.2 \mathrm{~mm}$,

doped with hydrogen up to $6.5 \mathrm{~mm}$;

Implanted atoms concentration up to $100 \mathrm{appm}$;

Temperature $20-800{ }^{\circ} \mathrm{C}$.

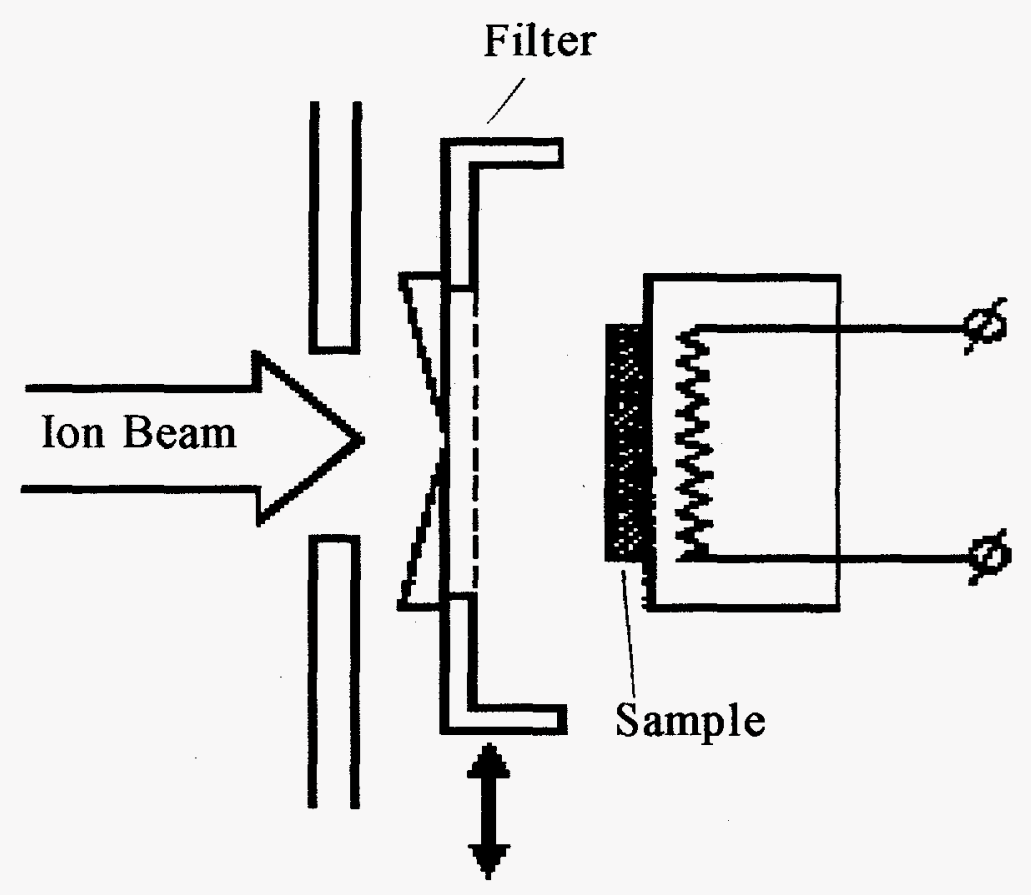

Fig.2.2. Irradiation technique for homogeneous ion doping.

\subsubsection{Expanded profiles formation}

For the formation of "expanded" damage profiles, including straggling zone, on the surface of irradiated sample, metal foil bended according to assigned law is used (fig.2.3).

Following parameters of irradiation are reached by using this technique:

Profile "expansion" coefficient

Incident particle energy:

$$
\begin{aligned}
& \text { alpha-particles } \\
& \text { protons }
\end{aligned}
$$

Impurity concentration/damage degree ratio $0-2000 \mathrm{appm} / \mathrm{dpa}$.

This technique enables to investigate on the single sample defect structure and material properties (by metallography, measurement of microhardness and lattice parameter, etc.) at various values of impurity concentration/damage degree ratio and different spectra of primary knock-on atoms. 


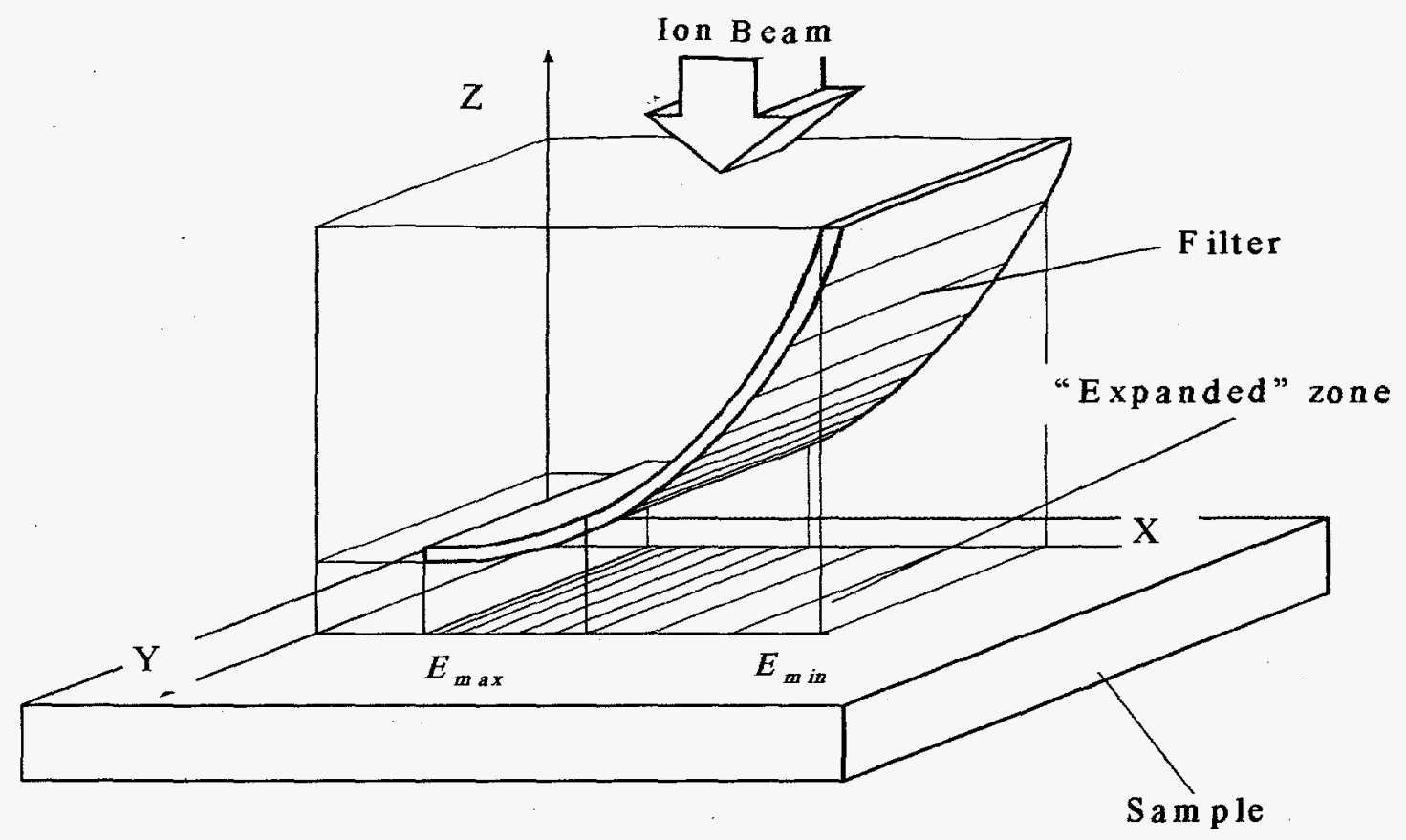

Fig.2.3. Irradiation technique for expanded profiles formation.

\subsubsection{Formation of separate doped zones in the sample}
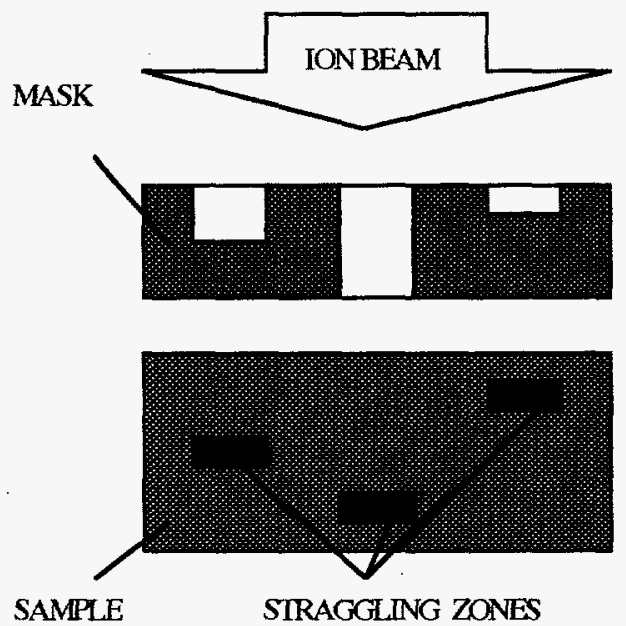

Fig.2.4. Irradiation technique for the formation of separate doped zones in the sample.

Irradiation of bulk Beryllium samples for metallography and mechanical tests is realized with use of stopping filters and masks, which provides doped zones formation at different depths in the sample and their spacial separation on the surface. As a result, there is non-irradiated region near any irradiated region of the 
sample. Depending on the material grain size, the dimensions of opened rectangular or round "windows" in the masks are chosen (fig.2.4). Usage of such geometry irradiation allows to study a formation of bubbles in doped zone, hardening of irradiated material, inclination to blister formation, and in case of brittle fracture (irradiated layer breaking off) - to determine critical parameters of the irradiation.

\subsubsection{Formation of periodically arranged regions of implantation}

For study of high gas impurity concentration influence on material structure by TEM methods, another irradiation technique is used. It consists in cylindrical stopping filters placing in front of the sample (fig.2.5).

Technical characteristics:

$\begin{array}{ll}\text { Filter diameter } & 10-100 \mu \mathrm{m} ; \\ \text { Particle energy } & 7-60 \mathrm{MeV} ; \\ \text { Impurity concentration } & \text { up to } 1000 \text { appm. }\end{array}$

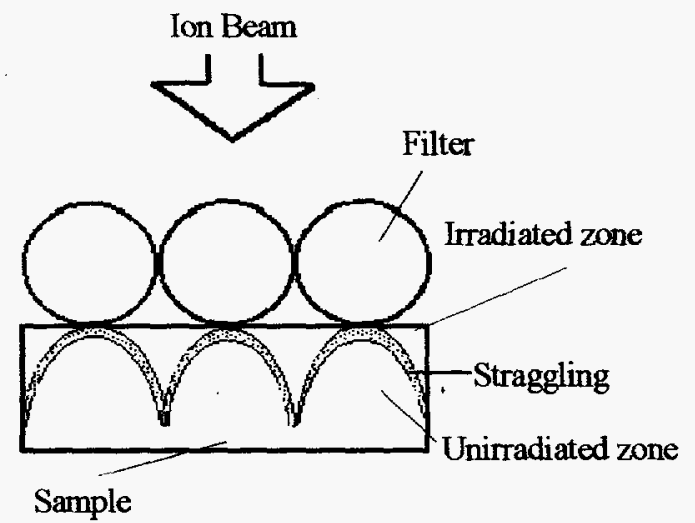

Fig.2.5. Irradiation technique for the formation of periodically arranged regions of implantation.

\subsubsection{HEAVY ION ACCELERATOR UKP 2-1}

Heavy ion accelerator UKP 2-1 (fig.2.6) is a tandem accelerator with two independent accelerating tracts and oilless pumping system. Due to high energy stability and wide accelerated mass range it allows to carry out precision nuclearphysical measurements of radiation damage and impurity concentration profiles in near-surface layers of material by Rutherford backscattering, nuclear reactions, ion channeling and PIXE methods. Besides this, the accelerator allows to carry out highdose irradiation experiments with material damage degree about dozens of dpa. 
Accelerator technical characteristics:

\begin{tabular}{ll} 
Accelerating voltage & $0.05-1.0 \mathrm{MeV}$; \\
Accelerating voltage stability & $0.015 \% ;$ \\
$\begin{array}{l}\text { Accelerated mass range } \\
\text { Ion beam current for: }\end{array}$ & $1-250 \mathrm{amu} ;$ \\
\multicolumn{1}{c}{ hydrogen } & \\
heavy ions & up to $100 \mu \mathrm{A}$, \\
Focal spot size & about $1 \mu \mathrm{A} ;$ \\
Scanning area & $0.01 \mathrm{~mm} ;$ \\
S & $30 \times 30 \mathrm{~mm}^{2}$.
\end{tabular}

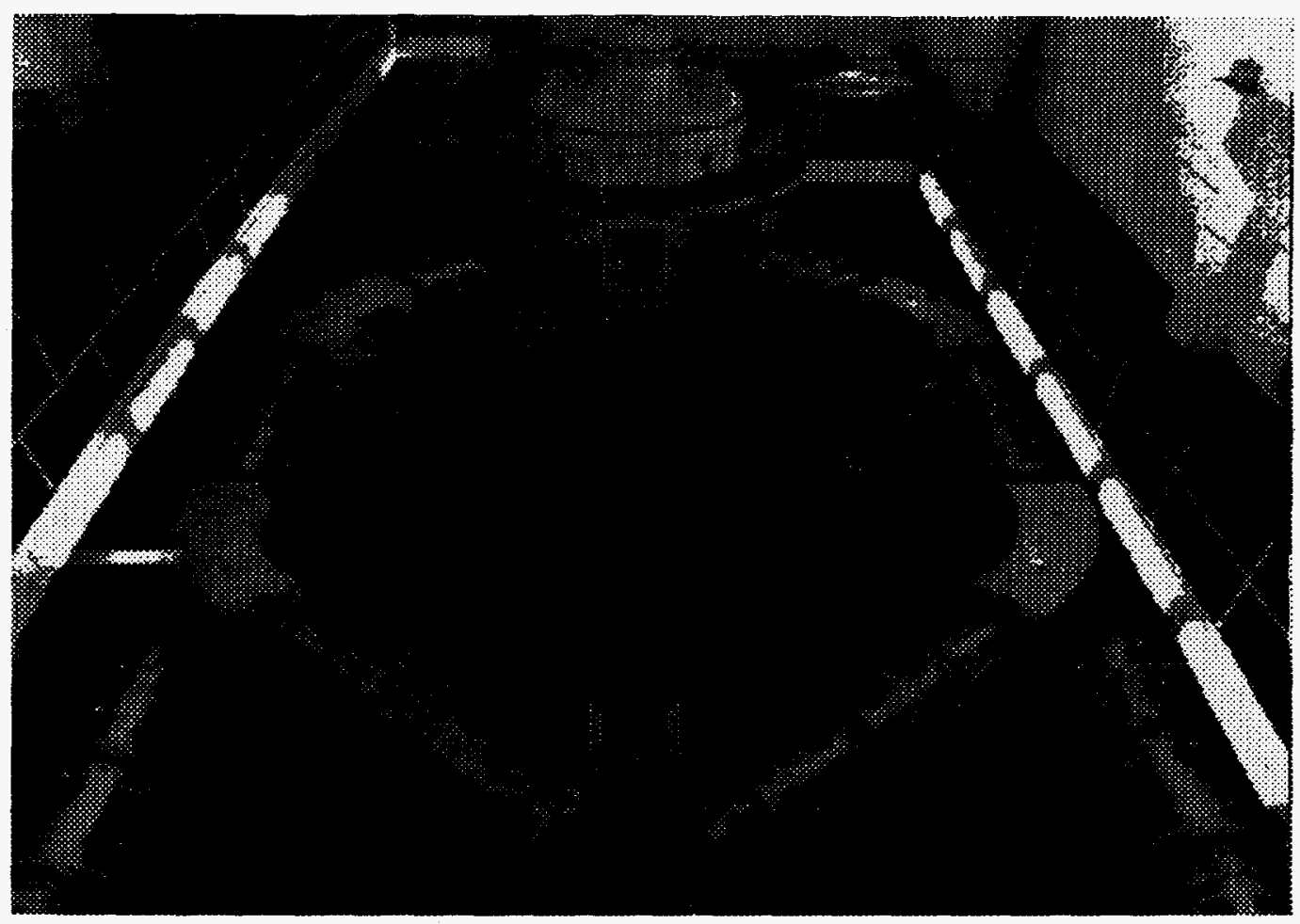

Fig.2.6. Heavy ion accelerator UKP 2-1.

Study of high-dose irradiation effects on the structure and properties of materials is carried out with use of this accelerator. Application of special techniques makes possible TEM-study of a defect structure along ion range in the material ("cross-section").

Modified device for a homogeneous ion doping is used as a target chamber for irradiation. Besides this, a universal target chamber is used, allowing simultaneous damage formation by ion irradiation and nuclear-physical measurements of damage and concentration profiles. 
Irradiated surface analysis by SEM and optical metallography allows to determine main irradiation parameters resulting in fatal changes of sample surface, and to estimate a possibility of radiation-enhanced and thermal restoration of largescale surface damage (blisters, cavities and so on) by intensive proton beam.

\subsubsection{NUCLEAR REACTOR IGR}

Pulse uran-graphite self-stopping thermal neutron reactor IGR has the following technical characteristics:

Power at the pulse mode

Maximum energy release

Fuel temperature

Coolant

Neutron flux density at the pulse mode
$10 \mathrm{GW}$

$5.2 \mathrm{GJ}$

$<1400 \mathrm{~K}$;

is absent;

$0.7 \times 10^{17} \mathrm{n} / \mathrm{cm}^{2} \mathrm{~s}$.

Central experimental channel diameter is $22.8 \mathrm{~cm}$. Ampule devices allow to realize irradiations in hydrogen or nitrogen environment. High reactor reactivity (3.4\%) provide minimum neutron pulse as short as $0.12 \mathrm{~s}$. Pulse heating of samples up to near-melting temperatures is possible.

\subsubsection{NUCLEAR REACTOR EWG 1 M}

The EWG.1M reactor - an advanced EWG.1 reactor - is a research watercooled heterogeneous thermal nuclear reactor with light-water moderator and coolant and beryllium reflector. The reactor core includes 30 water-cooled technological channels installed in three-circular row cells. An equivalent diameter of the core is $0.548 \mathrm{~m}$, height is $0.8 \mathrm{~m}$. In the central part of the reactor there is an experimental loop channel with a diameter of $0.164 \mathrm{~m}$ surrounded by beryllium displacer, in which it is possible to locate an apparatus including one or some tested fuel assemblies or containers with irradiated material samples. In the beryllium moderator 12 rods of the reactor reactivity compensation system are mounted. Core surrounding reflector has 10 regulating drums, which are the operating members of the reactor control and safety system.

Technical characteristics:

$\begin{array}{lll}\text { Reactor modification } & \text { EWG.1 } & \text { EWG.1M }\end{array}$ 


$\begin{array}{lll}\text { U-235 loading, } \mathrm{kg} & 6.7 \div 15.9 & 4.6 \\ \text { Fuel } & (\mathrm{U}, \mathrm{Zr}, \mathrm{Nb}) \mathrm{C} & \mathrm{U}, \mathrm{Zr} / \mathrm{Zr} \\ \text { Fuel temperature, } \mathrm{K} & 3400 & 390 \\ \text { Coolant } & \mathrm{H}_{2} \cdot \mathrm{N}_{2} & \mathrm{H}_{2} \mathrm{O} \\ \begin{array}{l}\text { Coolant temperature, } \mathrm{K} \\ \text { Thermal neutron flux density }\end{array} & 3100 & 370 \\ \text { in the core, } \mathrm{n} / \mathrm{cm}^{2} \mathrm{~s} & & \\ & 3.5 \times 10^{15} & 3.5 \times 10^{14}\end{array}$

The reactors described above are disposed at the former Semipalatinsk nuclear testing site and belong to the Institute of Atomic Energy NNC RK.

In the territory of Kazakhstan there is an industrial fast neutron reactor (BN350 ), situated in Aktau town and used for electric power production and for distillation of Caspian Sea water. This reactor does not belong to National Nuclear Center, but there is a possibility of high-dose irradiation of beryllium samples in it at neutron flux density about $10^{16} \mathrm{n} / \mathrm{cm}^{2} \mathrm{~s}$. Exposition in the central channel, where neutron flux and energy are maximum, allows to produce in beryllium samples radiation damage degree up to $30 \mathrm{dpa}$ in a reasonable amount of time.

\subsection{METHODS OF INVESTIGATION}

Following basic methods of investigation are used in SSRL:

1. Transmission electron microscopy (TEM) and techniques of TEM-specimens preparation including "cross-section" techniques allowing observation of the whole damaged zone in the single specimen.

2. Scanning electron microscopy and optical metallography.

3. Tensile tests and microhardness measurements.

4. X-ray diffraction.

5. Precision automatically controlled annealing of samples in vacuum and inert environment.

\subsubsection{TEM-SPECIMEN PREPARATION TECHNIQUE}

Initial processing of bulk Beryllium samples for TEM-specimen preparation includes electric discharge cutting, mechanical grinding and electrochemical 
polishing resulting in $3 \mathrm{~mm}$ diameter disks with thickness about $0.2 \mathrm{~mm}$. Specially modified device for visual control of surface quality "in situ" during electrochemical polishing, "ELIPOVIST", is used for choice and adjustment of electrolyte composition and polishing conditions.

Final thinning of TEM-specimens is realized by one-side jet electrochemical ,polishing in the original device with automatic switching off at the initial stage of specimen perforation.

Cross-sectioned TEM-specimens will be prepared by using a novel technique, which is less complicated than wide-known methods.

\subsubsection{TEM METHODS TO BE USED}

At the first step of research, study of beryllium microstructure includes determination of grain size, grain shape, grain orientation and peculiarities of dislocation structure.

This will be attained by photographing, processing and analysis of bright-field images of microstructure and corresponding diffraction patterns. Dislocations identification will be performed by standard method using the vanishing criterion $\mathbf{g} \mathbf{x}=0$, where $\mathbf{g}$ is the reflection vector and $\mathbf{b}$ is the Burgers. vector. Defocused images method D-2-1/2 will be used for estimating of strains in matrix.

At the further microstructural study of irradiated samples the regularities of evolution of dislocation structure, voids, bubbles and impurities distribution are to be determined depending on irradiation and post-irradiation treatment conditions. In some cases "in situ" experiments with specimen heating in TEM can be carried out.

Since the Beryllium is a material with a relatively low impurities solubility, a secondary phases precipitation on grain boundaries, dislocations and in the matrix is to be expected. These precipitates have significant influence on the plastic properties of material. Therefore a study of irradiation effect on impurities redistribution and secondary phases formation is desirable. Unfortunately, subcontractor do not possess an apparatus for high resolution microprobe analysis. It could be expedient to conduct such experiments jointly with LANL. 


\subsubsection{TENSILE TESTS AND MICROHARDNESS MEASUREMENTS}

For measurements of mechanical characteristics of beryllium (tensile strength, ductility, microhardness) tensile tests in the "INSTRON-1195" facility at various temperatures $\left(20-800^{\circ} \mathrm{C}\right)$ in vacuum $\left(3 \times 10^{-3} \mathrm{~Pa}\right)$ with deformation rates $10^{-2} \div 10^{-4} \mathrm{~s}^{-1}$ and microhardness measurements by Vickers method in the PMT-3 device with indenter loading of 50-200 g are planned.

\subsubsection{METALLOGRAPHIC METHODS}

Metallographic study includes sample surface grinding and polishing, chemical etching for microstructural features visualization, and image recording using "NEOPHOT-2" optical microscope and/or "REM-200" scanning electron microscope. Due to large focus depth, SEM will be used also for the analysis of fractured surfaces of samples after mechanical tests, including quantitative relief measurement by means of stereophotography.

It is reasonable to study impurities and their segregation effect on the fracture mode using high-resolutional SEM with microprobe analysis.

For study of large-scale surface damage and swelling in the irradiated zone, profilometry method will be applied allowing to detect relief roughnesses with accuracy of $100 \mathrm{~nm}$.

\subsubsection{X-RAY DIFFRACTION}

Precision measurements of lattice parameter in different grade beryllium samples, and determination of lattice periods of secondary phase particles will be performed in "DRON-3" X-ray diffractometer with copper, iron, or cobalt anode.

\subsubsection{POST-IRRADIATION ANNEALING TECHNIQUE}

For study of defect structure evolution as a result of post-irradiation annealing, special device is used, which includes small electric furnace with resistive heater and thermocouples, situated in the vacuum volume, and precision automatic temperature controller. The device provides temperature stability about $1 \%$ in the range of 50 $800{ }^{\circ} \mathrm{C}$ at residual pressure of $10^{-3} \mathrm{~Pa}$. There are a possibilities of annealing in the inert environment (Ar) and programmed step by step temperature variation. 


\section{MICROSTRUCTURAL CHARACTERIZATION OF POLYCRYSTAL BERYLLIUM MATERIAL.}

\subsection{INTRODUCTION}

Polycrystal Beryllium of (A-4) grade, produced by hot pressing at Ulba metal plant, was taken as a sample for study.

Its purity turned out to be not very high, as it is clear from undermentioned results, but this fact has enabled to test a suitability of our experimental techniques and methods more completely.

Grain size in analyzed samples was too large for the obtaining of any statistical information about grain size and grain shape by transmission electron microscopy (TEM). Therefore such information was obtained with use of optical metallography, while TEM-study was focused at the analysis of matrix defect structure.

\subsection{SPECIMEN PREPARATION AND EXPERIMENTAL PROCEDURE.}

\subsubsection{OPTICAL METALLOGRAPHY.}

Bulk beryllium cylinder with diameter of $17 \mathrm{~mm}$ was sliced by electric discharge cutting into plates with thickness about $0.4 \mathrm{~mm}$. Plates was mechanically grinded and polished using fine polishing powder. Polished plates was subjected to chemical etching in boiling $10 \%$ solution of $\mathrm{HOOCCOOH}$ in water during 2 minutes in order to visualize crystal grain boundaries.

Etched polished sections of beryllium samples were studied in Neophot-2 optical microscope. Structure images with magnifications from 100 to 400 were recorded onto photoplates. Measurements were carried out on photographic prints with total magnification of 400 . 


\subsubsection{TRANSMISSION ELECTRON MICROSCOPY.}

Bulk beryllium cylinder with diameter of $17 \mathrm{~mm}$ was sliced by electric discharge cutting into plates with thickness about $0.4 \mathrm{~mm}$. Plates were mechanically grinded up to $0.2 \mathrm{~mm}$ thickness. $3 \mathrm{~mm}$ diameter disks were cut from grinded plates in electric discharge device in order to avoid sample deformation. TEM-specimens ,were prepared from $3 \mathrm{~mm}$ diameter disks by one-jet electrochemical polishing in a mixture of $\mathrm{HClO}_{4}(200 \mathrm{ml}), \mathrm{C}_{2} \mathrm{H}_{5} \mathrm{OH}(700 \mathrm{ml})$ and $\mathrm{C}_{3} \mathrm{H}_{8} \mathrm{O}_{3}(100 \mathrm{ml})$ at room temperature, $20 \mathrm{~V}$, and $5 \mathrm{~mA}$. This solution was chosen from a lot of possible and known from literature compositions taking into account experimentally tested quality of polishing and accessibility of reagents.

TEM-study of beryllium samples was carried out in JEM-100 CX and EM125 transmission electron microscopes at accelerating voltage of 100 and $125 \mathrm{kV}$ and magnifications from 1000 to 100000 . Microstructure images and corresponding diffraction patterns were recorded onto photoplates. Diffraction pattern distances were measured directly at photoplates. Sizes, distances and densities of microstructural features were measured at magnified photographic prints.

\subsection{RESULTS OF MICROSTRUCTURAL STUDY.}

\subsubsection{OPTICAL METALLOGRAPHY RESULTS.}

Fig.3.1 shows a typical photograph of etched polished section of beryllium sample.

The material consists of polygonal grains with size ranging from about 2 to 50 $\mu \mathrm{m}$ without any preferential orientation. Size distribution of grain sections obtained using a series of micrographs is presented at fig.3.2. An average grain size value determined from histogram is equal to $8.5 \mu \mathrm{m}$.

\subsubsection{TEM RESULTS.}

Low magnification micrograph of Be sample structure is shown at fig.3.3. One can see a lot of second phase inclusions, visible as black spots. Volume content of second phase was estimated to be about $1 \%$, using low magnification TEM-images. 


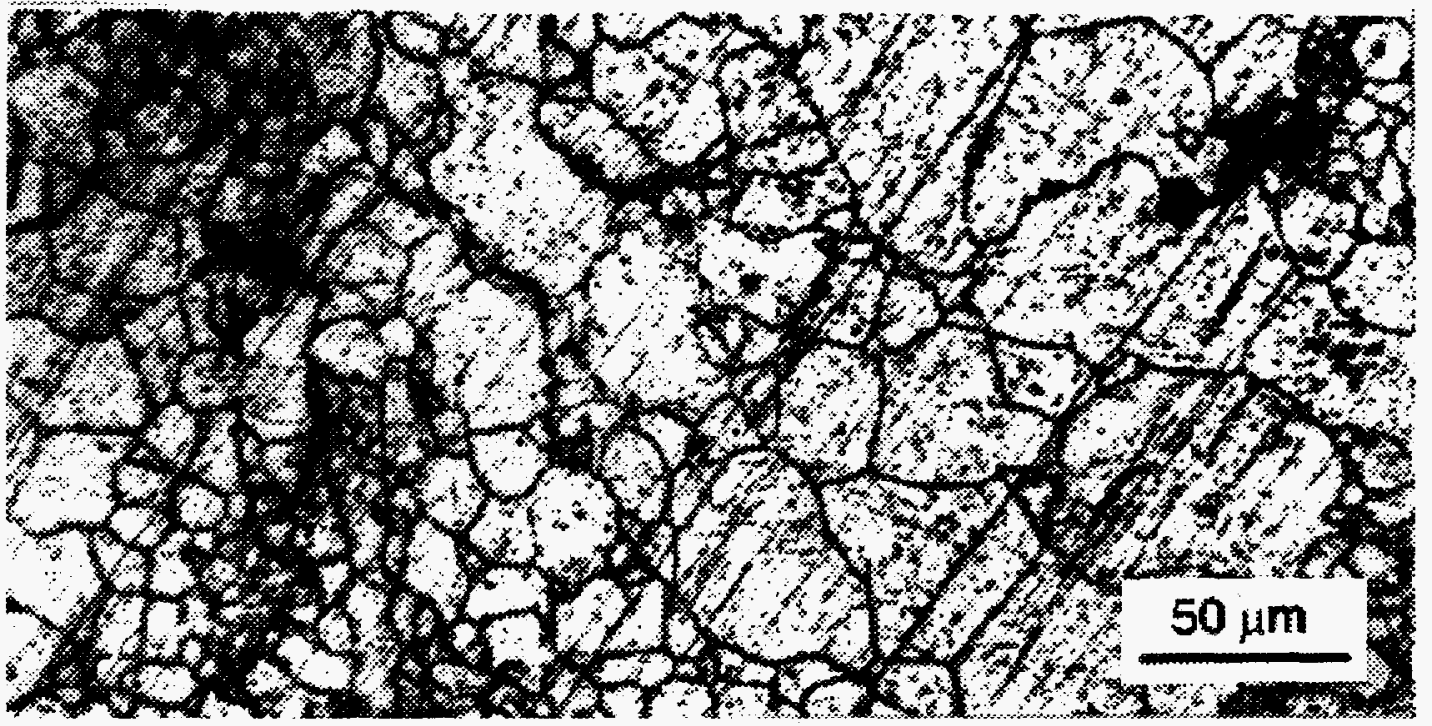

Fig.3.1. Optical micrograph of etched polished section of A-4 beryllium sample.

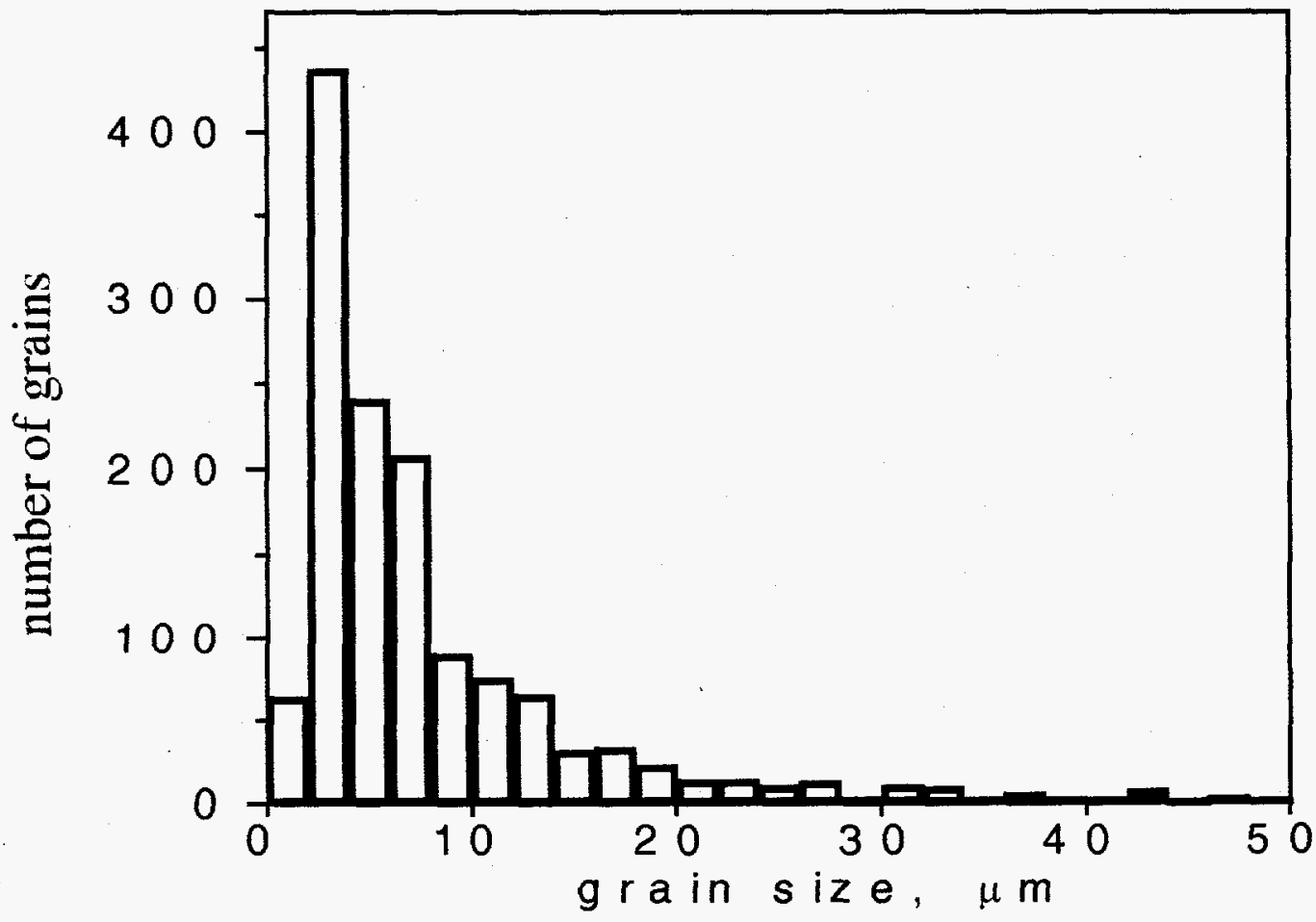

Fig.3.2. Histogram showing grain size distribution in A-4 beryllium. 


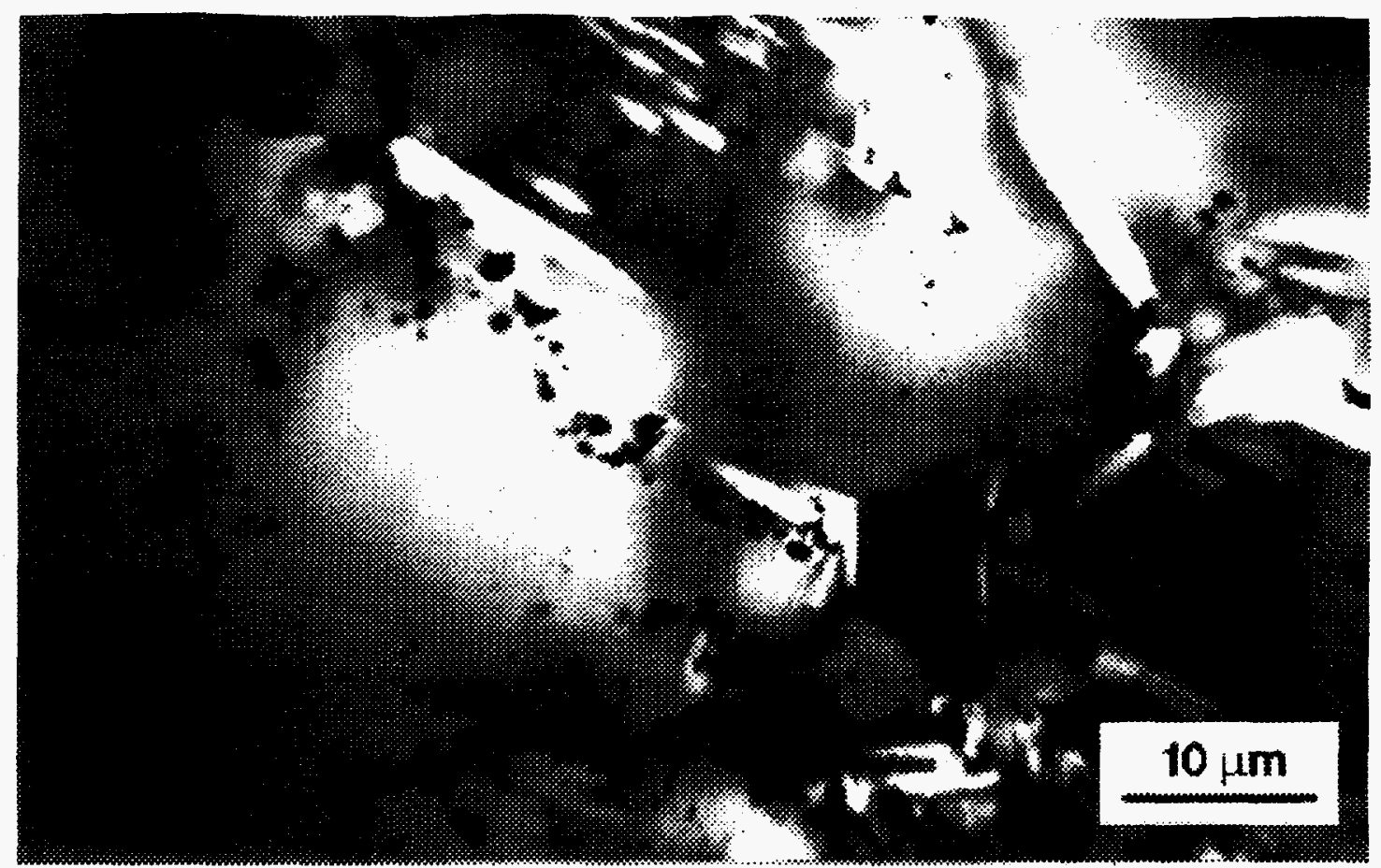

Fig.3.3. Low magnification TEM image of A-4 beryllium microstructure.

Specimen thickness was determined by stereophotography and its mean value for large areas at low magnification proved to be about 1 micron. Inclusions are situated near grain boundaries and randomly in grain matrix (see fig.3.4), in the latter case their size being somewhat smaller, as a rule . Fig.3.5 presents size distribution of inclusions calculated using a series of micrographs at magnification of 20000. Shape of particles was close to prismoidal, and mean value between largest and least dimensions of single particle was taken as particle size. As it is seen from histogram, size of inclusions ranges from about $50 \mathrm{~nm}$ to $1300 \mathrm{~nm}$ with average value $450 \mathrm{~nm}$.

Nature of inclusions was determined by means of electron diffraction, using matrix reflections for calibration. Lattice distances determined from diffraction patterns are well coincident with known distances for beryllium oxide, BeO. Dark field images in the $\mathrm{BeO}$ reflections show bright contrast of inclusions (see fig.3.6). It some occurrences oxide particles form conglomerates with diameter about $1000 \mathrm{~nm}$, as shown at fig.3.7.

Presence of $\mathrm{BeO}$ phase is confirmed by $\mathrm{X}$-ray diffraction, which shows welldefined series of $\mathrm{BeO}$ reflections. Some additional non-identified weak reflections 
were found by $\mathrm{X}$-ray diffraction, but any other than $\mathrm{BeO}$ second phase inclusions were not identified by electron diffraction.
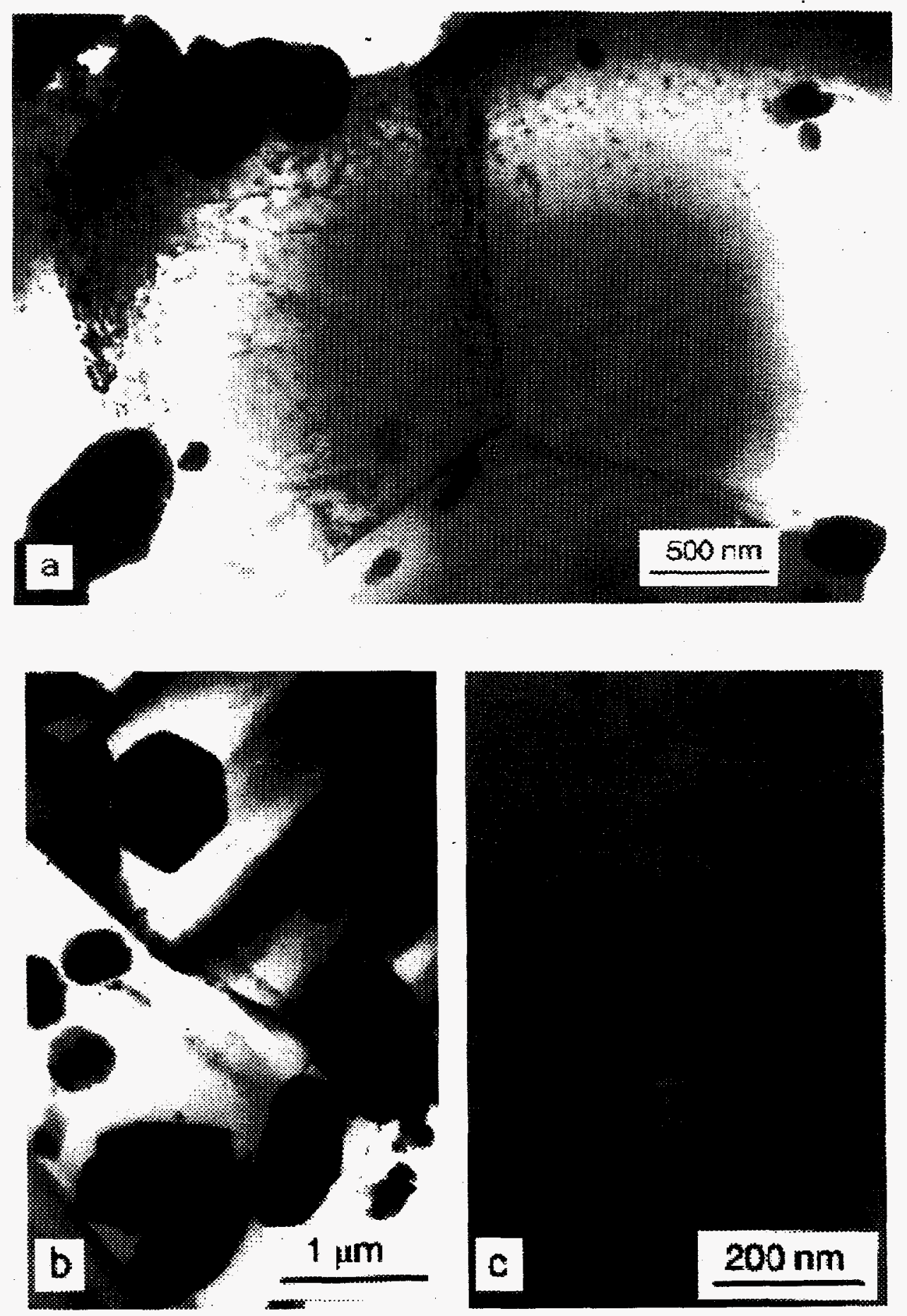

Fig.3.4. Second phase inclusions in A-4 beryllium: a) 40000 magnification; b) large particles near grain boundary at 20000 magnification; c) small particles in matrix at 100000 magnification. 


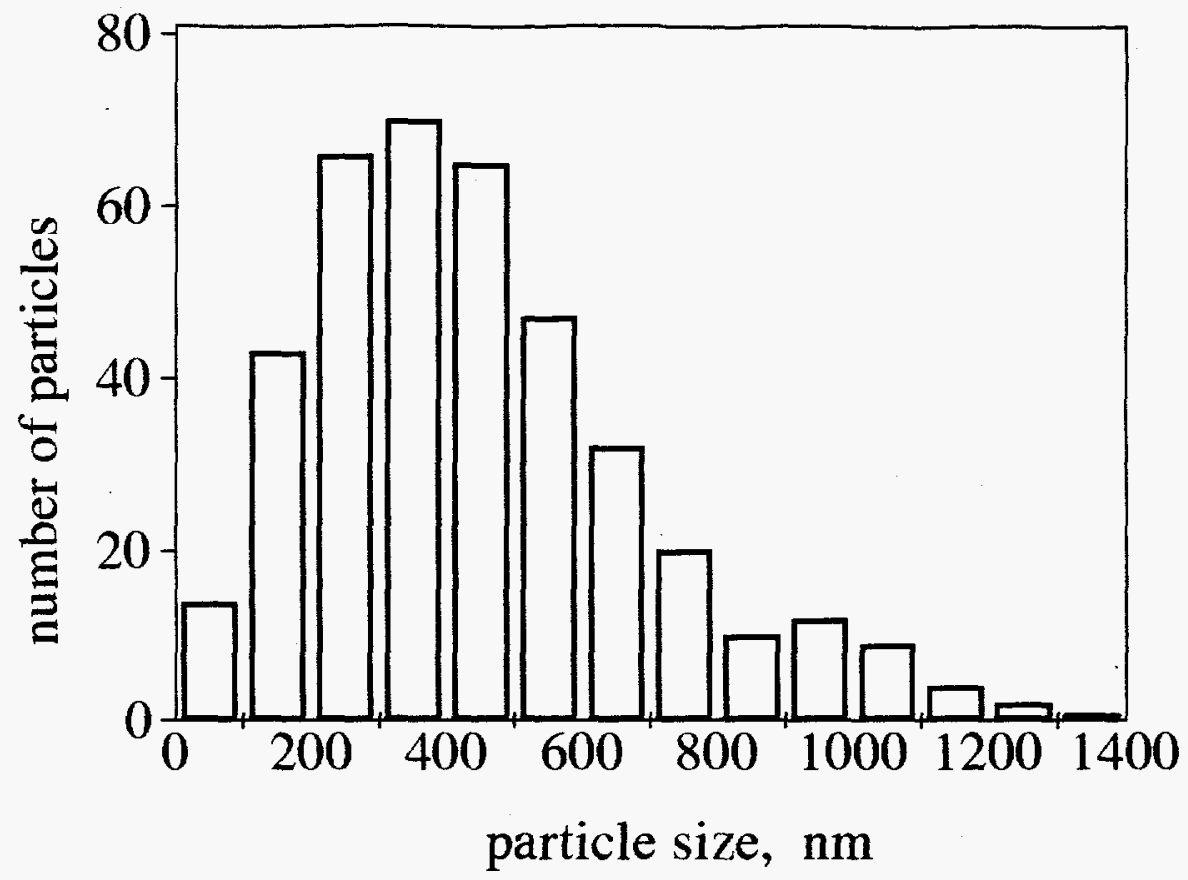

Fig.3.5. Histogram showing size distribution of second phase particles in A-4 beryllium.

It was found that intercrystalline interfaces in analyzed samples are wellformed grain boundaries, notwithstanding the material have been produced by hot pressing. Disorientation of adjacent grains is compensated by a network of grain boundary dislocations (fig.3.8). No cavities were observed in the samples, including near-boundary regions.

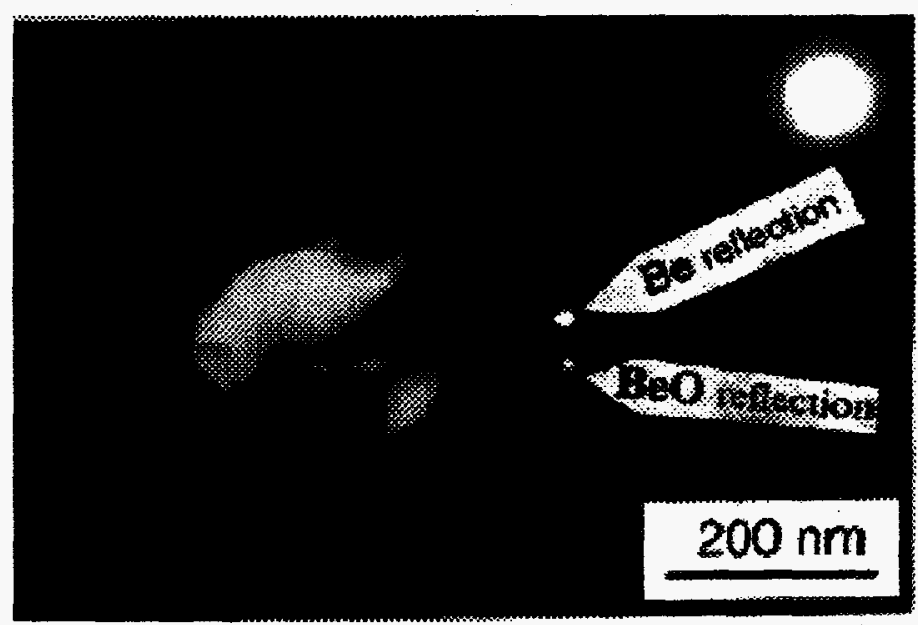

Fig.3,6. Dark field image of inclusion in BeO reflection. 

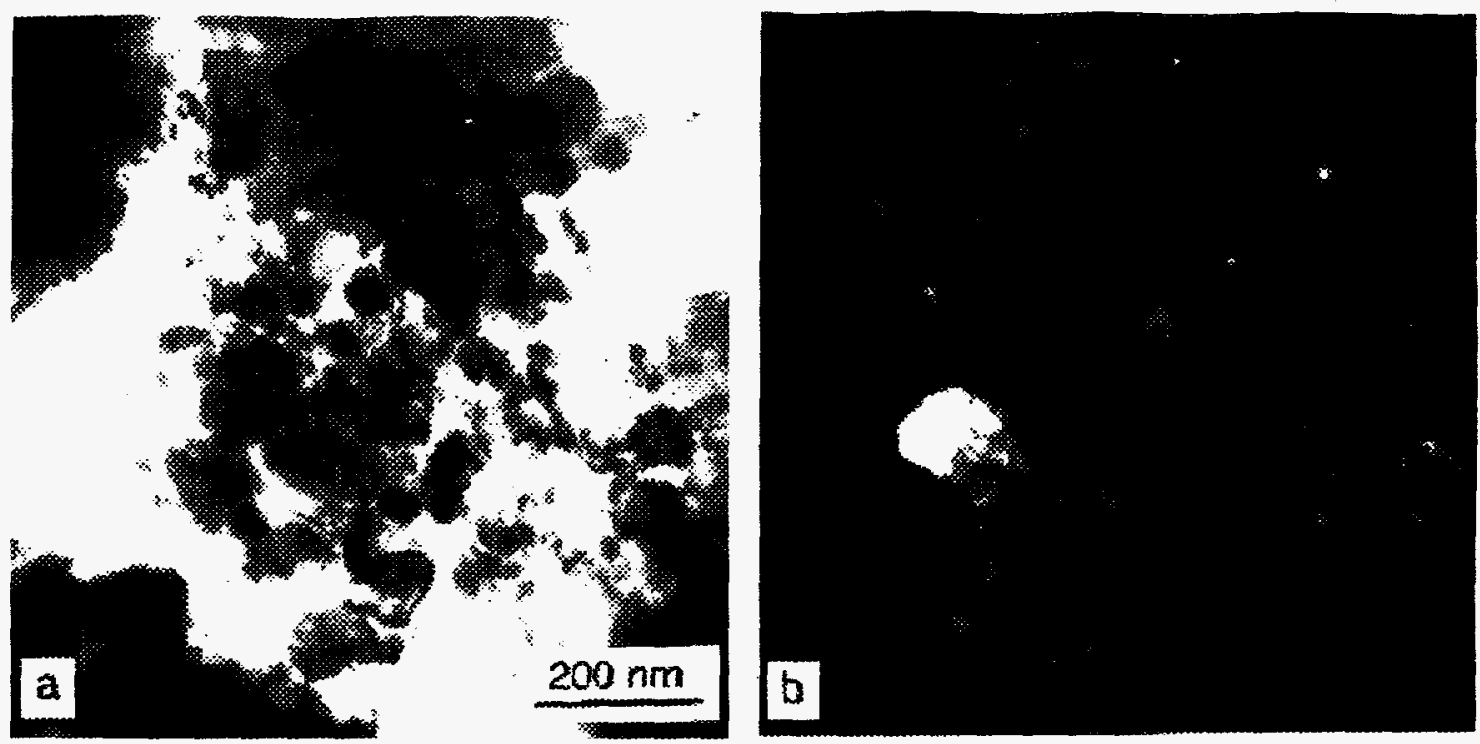

Fig.3.7. BeO particles conglomerate in A-4 beryllium: a) bright field; b) dark field image in $\mathrm{BeO}$ reflection.

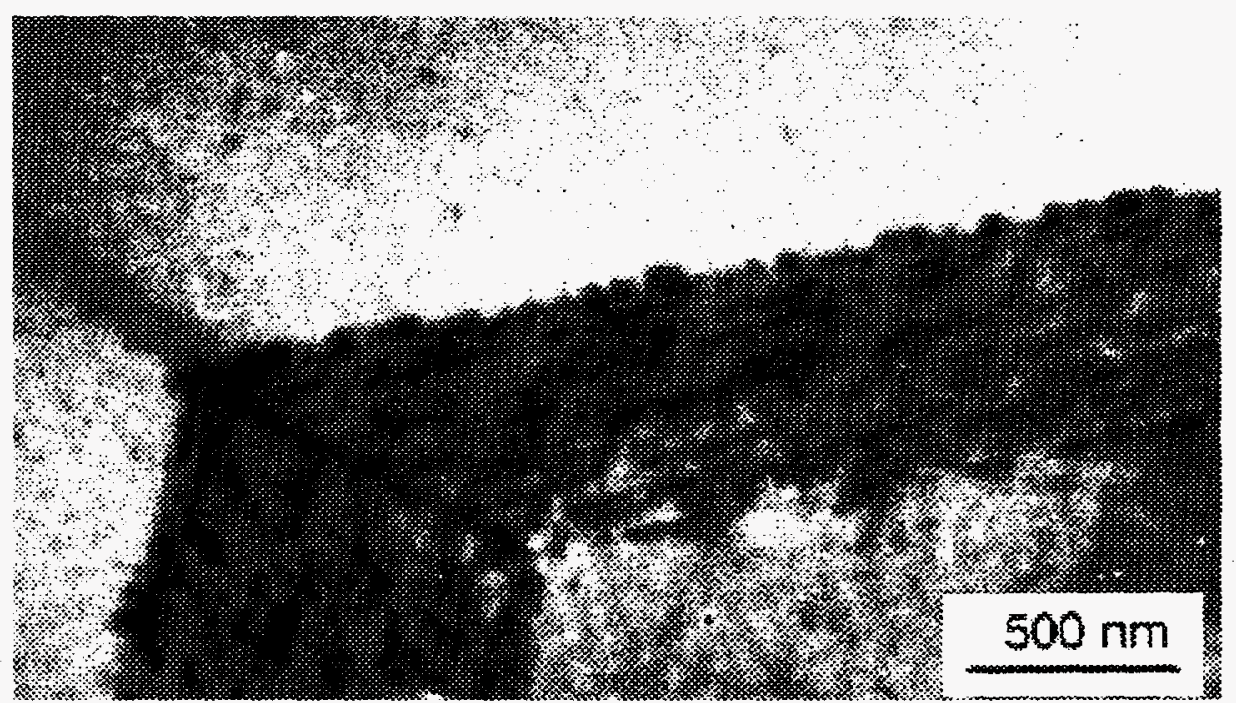

Fig.3.8. Grain boundary in A-4 beryllium.

Besides oxide particles, linear dislocations and small dislocation loops were found in the grain matrix (fig.3.9), with average dislocation density about $2 \times 10^{9}$ $\mathrm{cm}^{-2}$, as was estimated by random secant lines method. For a calculation of specimen thicknesses, the "extinction contours" method in a two-beam diffracting conditions was applied. Dislocation density is not uniform in a grain volume. In 
most cases crystal grains are divided by dislocation walls onto slightly disoriented blocks (fig.3.10).

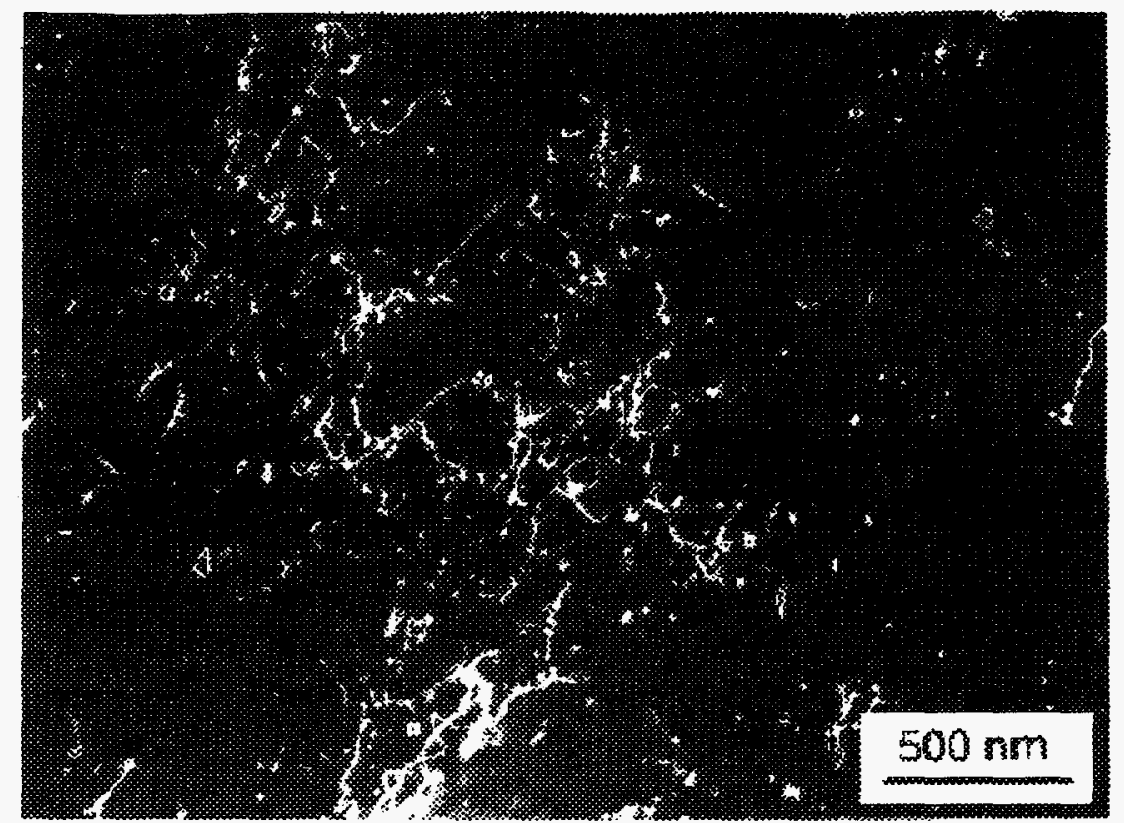

Fig.3.9. Dislocations and dislocation loops in matrix, dark field image.

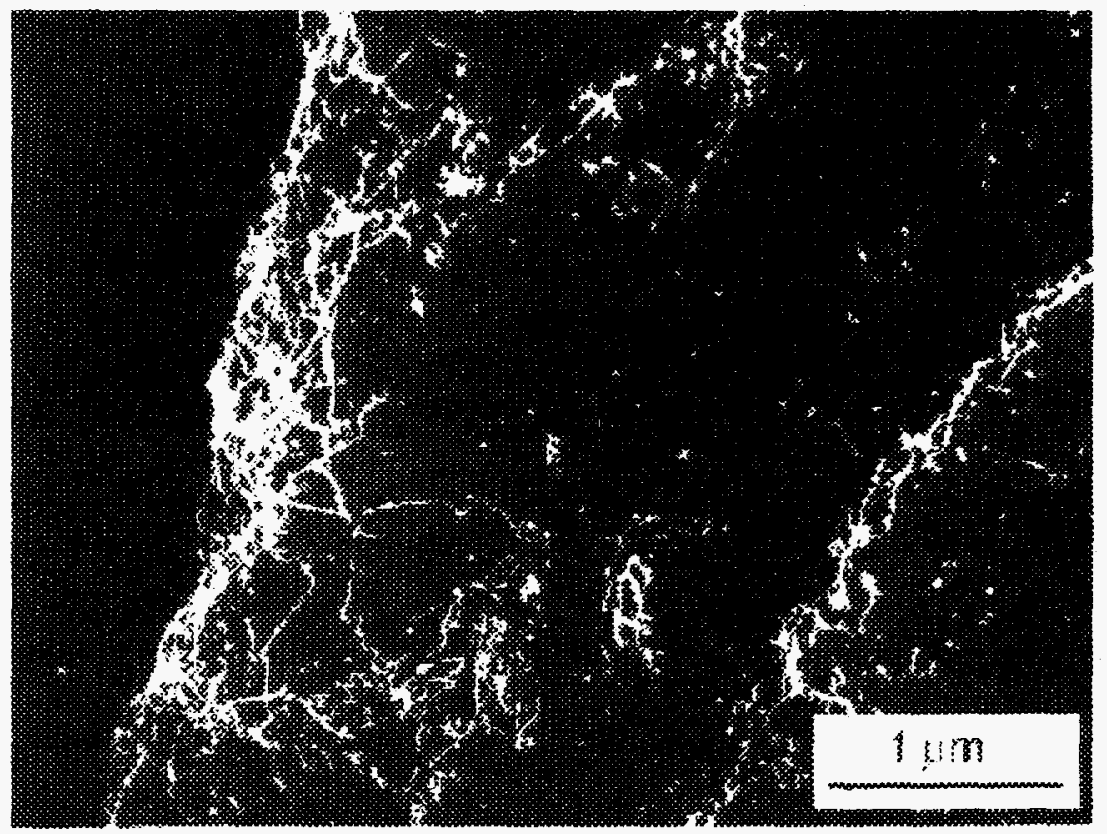

Fig.3.10.Dislocation walls in matrix, dark field image. 


\subsection{SUMMARY.}

The aforesaid results show that sufficiently complete information about microstructure of polycrystal beryllium material can be obtained by means of transmission electron microscopy in combination with optical metallography and Xray diffraction. The material analyzed in the present study is a polycrystal beryllium with an average grain size about $8.5 \mu \mathrm{m}$, well-formed grain boundaries and without cavities. Dislocation density in grain matrix is $210^{9} \mathrm{~cm}^{-2}$, taking into account dislocation walls. High contents of $\mathrm{BeO}$ inclusions (about $1 \%$ by volume) with average diameter of $400 \mathrm{~nm}$ was found in the material.

\section{TASK FORMULATION FOR THE DEVELOPMENT OF THE PROJECT FOR THE EXPERIMENTS ON INVESTIGATION OF BERYLLIUM MATERIALS BEHAVIOR UNDER CONDITIONS, CLOSE TO THERMO-NUCLEAR REACTOR (TNR).}

When choosing the materials and making an attempt to construct the first wall of the thermo-nuclear reactor, a number of the problems related to the studying the properties of beryllium under conditions of $\mathrm{He}$ and $\mathrm{H}$ atoms accumulation, intense radiation and temperature influence are left unsolved, as well as the task of production of Be coatings satisfying numerous requirements, called "TNR conditions".

One of the specific problems related to this type conditions and requiring a definite solution is the clearing up of the complex effect of gaseous impurities, radiation defects and the temperature on the physical-mechanical properties of beryllium and real beryllium products. Such problem can be divided into a number of sections: 
- structural and phase stability of Be and Be coatings under the intense radiation influence;

- gaseous swelling and gas-filled bubble behavior in Be and Be coatings under thermal and reactor irradiation influence;

- variation in the Be mechanical properties under the conditions of $\mathrm{He}$ and/or $\mathrm{H}$ ; atoms accumulation;

- variation of the mechanical properties of Be-substrate interface. 


\section{POSSIBLE EXPERIMENTS}

\subsection{EXPERIMENT A}

The experiment objective is investigation of structural stability and gaseous swelling of plasma-spraied beryllium.

\section{TASKS}

TASK A1. To create in the Be samples the inner helium- and hydrogen-doped zones with the concentrations of 10,100,200,500, $1000 \mathrm{appm} \mathrm{He}$ and/or 30,300,600, 1500,3000 appm $\mathrm{H}$ by alpha-particle and proton irradiation.

TASK A2. To execute post-irradiation thermal annealing of Be samples with various contents of $\mathrm{He}$ and/or $\mathrm{H}$ at the temperatures $500,700,900,1100{ }^{\circ} \mathrm{C}$ during $0.1,1$, $10,100,1000$ hours accompanied by specimen surface profilometering.

TASK A3. To prepare specimens by Be sample cutting, grinding, mechanical polishing, electrochemical polishing and etching. To study the specimen structures by transmission and scanning electron microscopy, and optical metallography.

TASK A4. To measure the microhardness of Be specimens with various contents of $\mathrm{He}$ and/or $\mathrm{H}$ along the bombarding particle ranges after annealing at 500, 700, 900, $1100{ }^{\circ} \mathrm{C}$ during $0.1,1,10,100,1000$ hours.

TASK A5. To carry out the processing and analysis of the data of profilometry, microstructure studies and measurements of Be sample microhardness after implantation of $\mathrm{He}$ and/or $\mathrm{H}$ atoms and post-irradiation annealing.

TASK A6. To prepare a final report, describing all completed task activities. 


\section{EXPECTED RESULTS:}

- The Be samples having interior closed $\mathrm{He}$ and/or $\mathrm{H}$ doped zones with concentrations of $10,100,200,500,1000 \mathrm{appm} \mathrm{He}$ and/or 30,300,600, 1500, 3000 appm $\mathrm{H}$ are to be produced.

- The Be specimens with various $\mathrm{He}$ and/or $\mathrm{H}$ atoms contents, annealed at 300, $500,700,900,1100^{\circ} \mathrm{C}$ during $0.1,1,10,100,1000$ hours are to be obtained. The data on sample surface profile measuring are also to be obtained.

- The experimental data on the defect structure and gaseous bubble evolution during post-irradiation annealing of the Be specimens with closed $\mathrm{He}$ and $\mathrm{H}$ zones are to be obtained by transmission and scanning electron microscopy, and optical microscopy.

- The experimental data on microhardness measuring along the bombarding particle ranges in Be specimens with various $\mathrm{He}$ and/or $\mathrm{H}$ contents after annealing at $300,500,700,900,1100^{\circ} \mathrm{C}$ during $0.1,1,10,100,1000$ hours are to be obtained.

- A final report on the results of structural, profilometric and metallographic studies, measurements of microhardness of the annealed Be samples having closed zones with various contents of $\mathrm{He}$ and/or $\mathrm{H}$ atoms is to be prepared.

\section{EXPERIMENT DESCRIPTION}

The beryllium samples having the dimensions $40 \times 7 \times 1 \mathrm{~mm}^{3}$ are irradiated by 23 $\mathrm{MeV}$ alpha-particles and/or $7 \mathrm{MeV}$ protons in the isochronous cyclotron U-150 M trough a thick mask with the holes of a diameter $3 \mathrm{~mm}$. As a result, the closed gaseous zones shaped as the disks of a diameter $3 \mathrm{~mm}$ and a thickness up to $100 \mu \mathrm{m}$ are produced in the material interior. A set of samples is irradiated in order to produce the zones with $\mathrm{He}$ concentrations of 10,100, 200, 500, 1000 appm and/or $\mathrm{H}$ concentrations $30,300,600,1500,3000 \mathrm{appm}$. The irradiation temperature is 100

${ }^{\circ} \mathrm{C}$. The irradiation conditions, the specimen number and the required cyclotron time 
are presented is Table 1a (Appendix A). It should be noted that a part of the samples, irradiated by alpha-particles, later are re-irradiated by protons too. As a result we shall have three groups of samples with the closed zones which will contain the helium, hydrogen and helium plus hydrogen atoms. Further, the irradiated samples will be subjected to the annealing at $300,500,700,900,1100{ }^{\circ} \mathrm{C}$ during 0.1 , $, 1,10,100,1000$ hours accompanied by specimen surface profilometering.

For the observation of $\mathrm{Be}$ microstructure along bombarding particle ranges and microhardness measurements, the annealed specimens are sliced, grinded and polished in cross-section. After specimen chemical etching, investigation of gaseous bubble development in the doped zone is carried out by TEM, SEM and optical metallography methods.

Microhardness measuring is carried out along ion range, including the straggling zone.

\section{TASK SCHEDULE}

The experiment is performed during 2 years(see Table 1a, APPENDIX A). The task A1, related to Be samples cyclotron irradiation, will be carried out during the first quarter of the first year of the project activity. Irradiated sample annealings, according to the task $\mathrm{A} 2$, are executed during the second and third quarters. The tasks A3, A4, related to microstructure studies and microhardness measurements, are

made each during a half of year. The tasks A5 and A6 are carried out during the last quarter of the second year.

\section{FINANCIAL INFORMATION}

Total cost of the experiment comprises $\$ 113883$. The first year of project activity requires $\$ 69399$, whereas the second year costs $\$ 44484$. Total financial information on each item of expenditures is presented in Tables $3 \mathrm{a}, 4 \mathrm{a}$ and $5 \mathrm{a}$ (Appendix A). 


\subsection{EXPERIMENT B.}

The experiment objective is the investigation of behavior of the mechanical properties and microstructure of plasma-spraied Be versus the implanted $\mathrm{He}$ and/or $\mathrm{H}$ atom concentrations and the implantation temperature.

\section{TASKS}

TASK B1. To implant Be tensile specimens by He atoms up to concentrations of 10 , $100,200,500$ appm and by $H$ atoms up to $30,300,600,1500$ appm at 100,500 and $800^{\circ} \mathrm{C}$.

TASK B2. To perform tensile tests of Be specimens at $20,500,800^{\circ} \mathrm{C}$ after $\mathrm{He}$ and $\mathrm{H}$ implantation up to various concentrations at various irradiation temperatures.

TASK B3. To carry out SEM investigations of the fracture surfaces of the tested Be specimens with various contents of $\mathrm{He}$ and $\mathrm{H}$ atoms.

TASK B4. To carry out TEM investigations of Be specimens with various contents of $\mathrm{He}$ and $\mathrm{H}$ atoms after mechanical testing.

TASK B5. To prepare a final report on the results of mechanical testing and microstructure investigation of the Be samples implanted by $\mathrm{He}$ and $\mathrm{H}$ atoms.

\section{EXPECTED RESULTS:}

- The Be tensile specimens implanted by He atoms up to the concentration of 10 , $100,200,500$ appm and $\mathrm{H}$ atoms up to $30,300,600,1500 \mathrm{appm}$ at various temperatures are to be produced.

- The basic mechanical properties of Be samples versus the concentrations of $\mathrm{He}$ and $\mathrm{H}$ atoms and implantation temperature are to be cleared up. 
- The basic regularities in variation of the Be specimen fracture nature versus the concentrations of $\mathrm{He}$ and $\mathrm{H}$ atoms and implantation temperature are to be determined.

- The basic regularities in Be microstructure changes after mechanical testing versus

the concentrations of $\mathrm{He}$ and $\mathrm{H}$ atoms, the implantation and mechanical testing temperature are to be obtained.

- A final report on the results of mechanical testing and TEM investigation of the Be samples implanted by $\mathrm{He}$ and $\mathrm{H}$ atoms up to various concentrations at various temperatures is to be prepared.

\section{EXPERIMENT DESCRIPTION}

The tensile specimens with the dimensions $40 \times 7 \times 0.2 \mathrm{~mm}^{3}$, prepared at LANL, are implanted gomogeneously through the volume by $\mathrm{He}$ atoms up to the concentrations of $10,100,200,500 \mathrm{appm}$ and by $\mathrm{H}$ atoms up to the concentrations of $30,300,600,1500$ appm using alpha-particle and proton irradiation at 100, 500 and $800{ }^{\circ} \mathrm{C}$ in the isochronous cyclotron $\mathrm{U}-150 \mathrm{M}$. The implantation conditions, the specimen number and the required cyclotron time are presented in Table $1 \mathrm{~b}$ (Appendix B). A part of samples is irradiated successively both by alpha-particles and by protons. As a result, we are to obtain three groups of irradiated samples: with helium, with hydrogen and with helium plus hydrogen atoms.

The irradiated and unirradiated samples will undergo tensile testings at deformation rates of $10^{-2} \div 10^{-4} \mathrm{~s}^{-1}$ at 20,500 and $800^{\circ} \mathrm{C}$ up to the fracture. By tensile diagrams, the material strength and ductility limit will be determined as an average values of the parameters obtained in three identical tests.

The investigation of nature of Be specimens fracture will be done by SEM technique. After SEM investigations the disks of a diameter $3 \mathrm{~mm}$ are cut from the fractured samples. TEM-specimens are prepared from these disks. As a result of TEM investigation of $\mathrm{Be}$ specimens the qualitative and quantitative data on dislocation densities, gaseous bubbles and particles, their distributions within matrix and along grain boundaries will be obtained. 


\section{SCHEDULE}

The proposed experiment is to be performed during 18 month (see table $2 \mathrm{~b}$, Appendix B). Task B1 will be completed during the first two quarters. Tasks B2, B3, $\mathrm{B} 4$ and B5 are to be carried out per quarter during the next 4 quarters.

\section{, FINANCIAL INFORMATION}

The experiment cost consists of the participant payments during 18 months (APPENDIX 1), equipment cost, material cost, travel cost, government taxes and overhead. Total cost of the experiment B comprises $\$ 245861$ (See Table $3 b, 4 b, 5 b$, APPENDIX B).

\subsection{EXPERIMENT C}

The experiment objective is the investigation of Be-substrate interface behavior depending on the $\mathrm{He}$ and/or $\mathrm{H}$ concentration under pulse reactor irradiation.

\section{TASKS}

TASK C1. To prepare the samples and the target devices for cyclotron irradiation, to determine the conditions for sample implantation by $\mathrm{He}$ and $\mathrm{H}$ atoms.

TASK C2. To perform the implantation of Be-substrate plates by $\mathrm{He}$ atoms up to $\mathrm{He}$ concentrations of $10,100,200,500 \mathrm{appm}$ and/or by $\mathrm{H}$ atoms up to $30,300,600$, 1500 appm at 100,500 and $800{ }^{\circ} \mathrm{C}$.

TASK C3. To carry out the calculations of the reactor power and the specimen temperatures at neutron fluxes of $1 \times 10^{16}, 5 \times 10^{16}, 1 \times 10^{17}, 5 \times 10^{17} \mathrm{n} / \mathrm{cm}^{2} \mathrm{~s}$ and to choose the irradiation regimes for pulse reactor testing of the Be-substrate samples.

TASK C4. To perform the reactor tests of Be-substrate plates with various contents of $\mathrm{He}$ and/or $\mathrm{H}$ atoms for interface strength. 
TASK C5. To carry out slicing, mechanical grinding and polishing, electrochemical treatment of the Be-substrate samples with $\mathrm{He}$ and/or $\mathrm{H}$ after reactor tests and to investigate the Be-substrate interface by methods of transmission, scanning electron microscopy and optical microscopy.

TASK C6. To measure the microhardness within the interface region of Be-substrate samples with various contents of $\mathrm{He}$ and $\mathrm{H}$ after reactor testing .

TASK C7. To perform processing and analysis of the results of reactor testings, microstructure studies and the measurements of microhardness for the Be-substrate samples with various contents of $\mathrm{He}$ and $\mathrm{H}$ atoms.

TASK C8. To prepare a final report on task performance.

\section{EXPECTED RESULTS:}

- The Be-substrate samples implanted at 100,500 and $800^{\circ} \mathrm{C}$ by $\mathrm{He}$ atoms to the concentrations $10,100,200,500$ appm and/or $\mathrm{H}$ atoms to the concentrations 30 , $300,600,1500$ appm are to be produced.

- The neutron flux, the required reactor power, and the sample temperature are to be calculated, and the irradiation regimes for pulse reactor testings of the $\mathrm{Be}-$ substrate samples with various contents of $\mathrm{He}$ and $\mathrm{H}$ atoms are to be chosen.

- The Be-substrate samples with various contents of $\mathrm{He}$ and/or $\mathrm{H}$ atoms, tested in the reactor at neutron fluxes $1 \times 10^{16}, 5 \times 10^{16}, 1 \times 10^{17}, 5 \times 10^{17} \mathrm{n} / \mathrm{cm}^{2} \mathrm{~s}$ are to be obtained.

- Critical reactor irradiation conditions for fracture of the Be-substrate samples along the interface are to be determined (resource testing). 
- The polished sections of the Be-substrate samples with various contents of $\mathrm{He}$ and $\mathrm{H}$ after reactor testings are to be prepared. Structural investigation of the Besubstrate interface is to be carried out by TEM, SEM and optical microscopy methods.

- The Be-substrate interface microhardness data for the samples with various contents of $\mathrm{He}$ and $\mathrm{H}$ after reactor testings are to be obtained.

- The final report on the results of reactor testings, structure and metallographic studies and measurements of microhardness of the Be-substrate interface for the samples with various contents of $\mathrm{He}$ and $\mathrm{H}$ atoms is to be prepared.

\section{EXPERIMENT DESCRIPTION}

The Be-substrate samples with the dimensions $40 \times 7 \times 1.5 \mathrm{~mm}^{3}$, having the $\mathrm{Be}$ layer of a thickness about $1 \mathrm{~mm}$, are irradiated in cyclotron by $50 \mathrm{MeV}$ alphaparticles and $30 \mathrm{MeV}$ protons in such way that the interface is implanted by $\mathrm{He}$ atoms up to the concentrations $10,100,200,500 \mathrm{appm}$, and by $\mathrm{H}$ atoms up to 30 , $300,600,1500$ appm at 100,500 and $800{ }^{\circ} \mathrm{C}$.

For reactor testing the most of samples are implanted at $100{ }^{\circ} \mathrm{C}$ by $\mathrm{He}$ up to $100 \mathrm{appm}$ and by $\mathrm{H}$ up to $300 \mathrm{appm}$ (see Table 2C, Appendix C). Successive irradiation by alpha-particles and protons will allow to produce three groups of the samples: with $\mathrm{He}$, with $\mathrm{H}$ and with $\mathrm{He}+\mathrm{H}$.

Before reactor testing, the ampoule device parameters are determined is such manner that the sample temperature varies from 800 to $1100^{\circ} \mathrm{C}$ at neutron fluxes $1 \times 10^{16} \div 1 \times 10^{17} \mathrm{n} / \mathrm{cm}^{2} \mathrm{~s}$ and various neutron pulse frequencies and intensities.

Reactor testings are carried out at neutron fluxes $1 \times 10^{16}, 5 \times 10^{16}, 1 \times 10^{17}$, $5 \times 10^{17} \mathrm{n} / \mathrm{cm}^{2} \mathrm{~s}$ with 13 tests per each flux value (see Table $3 \mathrm{C}$, Appendix C). Total test number is 52. After each testing investigation of irradiated samples is carried out in order to determine the state of the Be-substrate interface.

After reactor testings the fracture surfaces of all fractured samples are studied by SEM technique. The rest specimens are cut in the cross section and, after mechanical grinding, polishing and/or electrochemical treatment, the region of Be- 
substrate interface is investigated by TEM, SEM, optical microscopy, and microhardness measurement methods.

Basing on all obtained results of reactor testings, post-reactor structural studies and microhardness measurements, a conclusion on the stability of the Be-substrate interface under conditions close to TNR is made, the critical parameters of irradiation resulting in material fracture are determined.

\section{SCHEDULE}

This experiment is performed during three years. Preparation and execution of cyclotron sample implantation by $\mathrm{He}$ and/or $\mathrm{H}$ atoms (Tasks $\mathrm{C} 1$ and $\mathrm{C} 2$ ) are expected to be completed during the first three quarters. In the fourth quarter of the first year the parameters of reactor testing (Task C3) are calculated; during the first half of the second year all reactor testings are to be performed (Task C4). During the second half of the second year structural investigations of samples after reactor testings (Task C5) are carried out. Microhardness measurements are performed in the first half of the third year (Task C6). During the third quarter of the third year accumulation, processing and analysis of all experimental data concerning the properties of the Be-substrate interface are to be done (Task C7).

The project activity is completed at the fourth quarter of the third year by the final report on the results of reactor testing of the Be-substrate samples implanted by $\mathrm{He}$ and $\mathrm{H}$.

\section{FINANCIAL INFORMATION}

The experiment cost consists of a participant payments, equipment expenditures, material purchase, travel cost, government taxes and overhead. Participant payments comprise $\$ 190$ daily (Appendix 1).

Participants will work 110 days per year, so total annual participant payments comprise $\$ 22800$. The equipment cost is composed of the cyclotron rent $(\$ 98000)$, a price of a microhardnessmeter ( $\$ 10000)$, a price of a computer, a printer, a xerox $(\$ 5800)$ and a payment for reactor irradiation (\$ 122500). Expenditure for working materials (abrasives, chemical reagents, photomaterials and stationery) requires annually $\$ 1300$. The Travel cost comprises $\$ 20000$. The overhead comprises $10 \%$ of 
the sum of the payment lost, the equipment cost, the material cost and the travel cost. The total cost of the experiment comprises $\$ 384032$, including $\$ 159214$ during the first year, $\$ 179784$ during the second year, and $\$ 45034$ during the third year.

Complete financial information for each item of expenditures per each year is given in Tables 4c, 5c, 6c and 7c (Appendix C).

\subsection{EXPERIMENT D.}

The experiment objective is TEM investigation of the defect structure and gaseous bubble evolution during post-irradiation thermal annealing of Be samples implanted by $\mathrm{He}$ and $\mathrm{H}$ atoms up to high concentrations.

\section{TASKS}

TASK D1. To carry out Be samples implantation by He atoms up to the concentrations $100,200,500,1000$ appm at 100,500 and $800{ }^{\circ} \mathrm{C}$.

TASK D2. To carry out Be sample implantation by $H$ atoms up to the concentrations $300,600,1500,3000$ appm at 100,500 and $800^{\circ} \mathrm{C}$.

TASK D3. To carry out the annealing of the samples with $\mathrm{He}$ and/or $\mathrm{H}$ at 300,500 , $700,900,1100{ }^{\circ} \mathrm{C}$ during $0.1,1,10,100,1000$ hours.

TASK D4. To prepare TEM-specimens from the samples with $\mathrm{He}$ and/or $\mathrm{H}$ annealed at $300,500,700,900,1100^{\circ} \mathrm{C}$.

TASK D5. To carry out TEM investigation of microstructure of the Be specimens with various contents of $\mathrm{He}$ and/or $\mathrm{H}$ atoms, annealed at $300-1100^{\circ} \mathrm{C}$ during 0.1 1000 hours. 
TASK D6. To perform processing and analysis of the results of TEM investigations of the Be specimens after $\mathrm{He}$ and/or $\mathrm{H}$ implantation and post-irradiation annealing, to prepare the final report.

\section{EXPECTED RESULTS}

- The Be samples implanted by $\mathrm{He}$ atoms up to the concentrations 100, 200, 500, 1000 appm at 100,500 and $800{ }^{\circ} \mathrm{C}$ are to be produced.

- The Be samples implanted by $\mathrm{H}$ atoms up to the concentrations $300,600,1500$, 3000 appm at 100,500 and $800{ }^{\circ} \mathrm{C}$ are to be produced.

- The Be samples with $\mathrm{He}$ and/or $\mathrm{H}$, annealed at $300,500,700,900,1100{ }^{\circ} \mathrm{C}$ during $0.1,1,10,100$ and 1000 hours are to be produced.

- The TEM-specimens from the Be samples, implanted by $\mathrm{He}$ and/or $\mathrm{H}$ and annealed at $300-1100{ }^{\circ} \mathrm{C}$ during $0.1-1000$ hours, are to be produced.

- The TEM investigation of microstructure of the specimens with various contents of $\mathrm{He}$ and/or $\mathrm{H}$ atoms, annealed at $300-1100{ }^{\circ} \mathrm{C}$ during $0.1-1000$ hours, is to be performed.

- Processing and analysis of the results of TEM investigation of Be specimens after $\mathrm{He}$ and/or $\mathrm{H}$ implantation and post-irradiation annealing are to be carried out. The final report is to be prepared.

\section{EXPERIMENT DESCRIPTION}

The Be samples ( 36 disks of a diameter $3 \mathrm{~mm}$ ) are irradiated by $1 \mathrm{MeV}$ alphaparticles and protons in heavy-ion accelerator UKP $2-1$ at 100,500 and $800{ }^{\circ} \mathrm{C}$ in a special target device. The set of samples is irradiated up to He concentration 100 , $200,500,1000$ appm and/or $\mathrm{H}$ concentration 300,600,1500,3000 appm with a doped layer thickness about $1 \mu \mathrm{m}$. 
The irradiated samples annealing is performed in vacuum at $300,500,700$, $900,1100{ }^{\circ} \mathrm{C}$ during $0.1,1,10,100,1000$ hours. Further, TEM-specimens are made from these samples by jet electropolishing technique.

TEM investigation of objects is aimed, mainly, to obtaining quantitative and qualitative information about evolution of gaseous bubbles, dislocation structure, second-phase particles and impurities redistribution in the material. Application of the specific irradiation technique gives a possibility to study at one TEM-specimen at once three zones: the zone irradiated "by shooting through", the straggling zone and unirradiated part of a specimen, making significantly easier the comparative structural study.

\section{SCHEDULE}

The experiment $\mathrm{D}$ is performed during 2 years (see Table 10, Appendix D). The tasks D1, D2 are carried out during the first and second quarters of the first year respectively. The task D3, related to long-termed post-irradiation annealing, is executed during the third and fourth quarters of the first year. The task D4 is executed during the first quarter, D5 during the second and third quarter, D6 during the fourth quarter of the second year.

\section{FINANCIAL INFORMATION}

To perform the experiment $\mathrm{D}, \$ 91784$ is required, including $\$ 46970$ during the first year and $\$ 44814$ during the second year. Complete financial information concerning each item of expenditure every year is presented in Tables $3 d, 4 d$ and $5 d$ (Appendix D).

\subsection{EXPERIMENT E}

The experiment objective is TEM study of phase-structural transformations in Be with various $\mathrm{He}$ and $\mathrm{H}$ contents irradiated by protons up to 1, 5 and $30 \mathrm{dpa}$ at 500 and $800{ }^{\circ} \mathrm{C}$. 


\section{TASKS}

TASK E1. To carry out the Be samples implantation by He atoms up to the concentrations $10,100,200,500,1000 \mathrm{appm}$ at $100{ }^{\circ} \mathrm{C}$.

, TASK E2. To carry out the Be samples implantation by $\mathrm{H}$ atoms up to the concentrations $30,300,600,1500,3000$ appm at $100{ }^{\circ} \mathrm{C}$.

TASK E3. To perform $1 \mathrm{MeV}$ proton irradiation of the Be samples with various $\mathrm{He}$ and/or $\mathrm{H}$ contents up to 1 and $5 \mathrm{dpa}$ at 500 and $800{ }^{\circ} \mathrm{C}$.

TASK E4. To perform $1 \mathrm{MeV}$ proton irradiation of the Be samples with various $\mathrm{He}$ and/or $\mathrm{H}$ contents up to $30 \mathrm{dpa}$ at 500 and $800^{\circ} \mathrm{C}$.

TASK E5. To prepare TEM-specimens from the samples with various $\mathrm{He}$ and/or $\mathrm{H}$ contents, irradiated by $1 \mathrm{MeV}$ protons up to 1,5 and 30 dpa at 500 and $800{ }^{\circ} \mathrm{C}$.

TASK E6. To carry out TEM investigation of microstructure of the Be specimens with various contents of $\mathrm{He}$ and/or $\mathrm{H}$,irradiated by $1 \mathrm{MeV}$ protons up to 1,5 and 30 dpa at 500 and $800{ }^{\circ} \mathrm{C}$.

TASK E7. To carry out processing and analysis of the results of TEM investigation of the Be specimens after $\mathrm{He}$ and/or $\mathrm{H}$ implantation and proton irradiation up to 1 , 5 and 30 dpa at 500 and $800{ }^{\circ} \mathrm{C}$.

TASK E8. To prepare the final report on the results of microstructural studies of $\mathrm{Be}$ with various contents of $\mathrm{He}$ and/or $\mathrm{H}$ atoms, irradiated by $1 \mathrm{MeV}$ protons up to 1,5 and 30 dpa at 500 and $800{ }^{\circ} \mathrm{C}$. 


\section{EXPECTED RESULTS:}

- The Be samples implanted by $\mathrm{He}$ atoms at $100^{\circ} \mathrm{C}$ up to concentrations 10,100 , $200,500,1000 \mathrm{dpa}$ are to be produced.

- The Be samples implanted by $\mathrm{H}$ atoms at $100^{\circ} \mathrm{C}$ up to concentrations 30,300 , $600,1500,3000$ dpa are to be produced.

- The Be samples with various contents of $\mathrm{He}$ and/or $\mathrm{H}$ atoms, irradiated by 1 $\mathrm{MeV}$ protons up to 1 and $5 \mathrm{dpa}$ at 500 and $800^{\circ} \mathrm{C}$ are to be produced.

- The TEM-specimens are to be prepared from Be samples with various contents of $\mathrm{He}$ and/or $\mathrm{H}$ atoms, irradiated by protons up to 1,5 and $30 \mathrm{dpa}$ at 500 and 800 ${ }^{\circ} \mathrm{C}$.

- The quantitative and qualitative data are to be obtained as a result of TEM investigation of microstructure of $\mathrm{Be}$ with various contents of $\mathrm{He}$ and/or $\mathrm{H}$ atoms, irradiated by protons up to 1,5 and $30 \mathrm{dpa}$ at 500 and $800^{\circ} \mathrm{C}$.

- Processing and analysis of the results of TEM study of phase-structural transformation in $\mathrm{Be}$ with various $\mathrm{He}$ and $\mathrm{H}$ contents, irradiated by protons up to 1, 5 and 30 dpa at 500 and $800{ }^{\circ} \mathrm{C}$ are to be carried out, a final report is to be prepared.

\section{EXPERIMENT DESCRIPTION}

The Be samples ( 36 disks of a diameter $3 \mathrm{~mm}$ ) are irradiated by $1 \mathrm{MeV}$ alphaparticles and protons in heavy-ion accelerator UKP 2-1 at $100 \mathrm{C}$ in a special target device. The set of samples is irradiated up to He concentration 10, 100, $1000 \mathrm{appm}$ and/or $\mathrm{H}$ concentration $30,300,3000$ appm with a doped layer thickness about 1 $\mu \mathrm{m}$. Then the samples implanted by $\mathrm{He}$ and/or $\mathrm{H}$ atoms are reirradiated by intense proton beam up to 1,5 and $30 \mathrm{dpa}$ at 500 and $800^{\circ} \mathrm{C}$. TEM-specimens are prepared from irradiated samples by jet electrochemical polishing. 
TEM analysis of irradiated Be specimens is aimed mainly to the obtaining of qualitative and quantitative information on the evolution of gaseous bubbles, dislocation structure, impurities redistribution and secondary phase particles formation.

\section{SCHEDULE}

The experiment $\mathrm{E}$ is performed during 2 years. Each task is carried out during one quarter (see Table 1e, Appendix E).

\section{FINANCIAL INFORMATION}

To perform the experiment E, \$94960 is required, including \$ 50146 during the first year and $\$ 44814$ during the second year. Complete financial information concerning each item of expenditure every year is presented in Tables $4 \mathrm{e}, 5 \mathrm{e}$ and $6 \mathrm{e}$ (Appendix E).

\section{CONCLUSION}

As a result of present agreement tasks performance, and looking through similar works executed in the framework of the ITER program by member states, as well as taking in mind the possibilities available and the existing experimental base, we propose the following formulation of the project on investigation of $\mathrm{Be}$ and $\mathrm{Be}$ coatings: "Complex simulation of fusion reactor radiation and thermal effect on the beryllium structure and properties".

The project aim is to study the beryllium (Be coatings) structure and properties under the conditions simulating radiation and thermal effect in TNR, to determine the critical parameters needed for choice of engineering and technological solutions related to creation of the first wall of ITER. A performance of the proposed tasks allows to solve the following problems:

- swelling of beryllium deposited onto a substrate by plasma spraying or another technique, variation of its physical mechanical properties in presence of gaseous impurities, grain-boundary effects: embrittlement, cracking etc.; 
- investigation of the beryllium-substrate interface behavior under conditions of intense irradiation and gaseous impurities accumulation;

- study of temperature cycling effect on a Be coating and its behavior under neutron irradiation accompanied by accumulation of gaseous impurities and radiation defects;

- phase-structural transformations in Be under the conditions of simultaneous effect of high-level damage and high concentrations of $\mathrm{He}$ and $\mathrm{H}$ atoms.

The experimental base available at NNC RK allows to perform the proposed experiments on volume doping of bulk Be samples and their radiation heating under conditions close to TNR. The list of proposed experiments is incomplete due to limited report volume. The description of the experiments on simulation of the complex effect of $\mathrm{He}$ and/or $\mathrm{H}$ atoms on various properties of $\mathrm{Be}$ and $\mathrm{Be}$ coatings under intense proton and neutron irradiation and thermocycling has suffered the most.

\section{REFERENCES}

1. Cascade-cluster defects in Molybdenum irradiated by protons, alpha-particles, fission products and ions - in Russian. Vestnik atomnoy nauki i tekhniki, 1981, $3(17)$.

2. Radiation damages in Molybdenum irradiated by protons and alpha-particles - in Russian. Fizika i himiya obrabotki materialov, 1986, N.1.

3. NMR and TEM study of neutron-irradiated copper - in Russian. In "Radiation defects in metals", Nauka, Alma-Ata, 1988, p.55-58. 
4. Peculiarities of radiation swelling of copper irradiated by xenon and copper ions with energy of $1 \mathrm{MeV} / \mathrm{amu}$ - in Russian. Preprint OIYaI (Dubna), 1988, P14$88-440$.

5. Defect accumulation in iron at proton irradiation. Radiation Effects Express, 1988 , v.2, p.127-132.

6. Radiation damage and hardening of molybdenum in the straggling zone of 29 $\mathrm{MeV}$ alpha-particles - in Russian. Vestnik atomnoy nauki i tekhniki, 1988, 2(44).

7. TEM and $\mathrm{x}$-ray study of alpha-particle - and neutron irradiated molybdenum in Russian. In "Charge particle accelerators and radiation physics", Moscow, 1988, p.76-82.

8. The effect of 5-30 MeV proton irradiation on the defect formation in molibdenum - in Russian. Fizica metallov i metallovedenie, 1991, N. 2, p.165171.

9. TEM study of defect structure in silicon along a range of low energy nitrogen ions - in Russian. Poverkhnost: Fizica, khimiya, mekhanica, 1992, N 1, p.48-55.

10. Microstructure and hardening of $0 \mathrm{Kh} 16 \mathrm{~N} 15 \mathrm{M} 3 \mathrm{~B}$ steel irradiated by alphaparticles and protons - in Russian. In "Modification of construction materials properties by charged particle beams", Tomsk, 1994, v.1, p.176.

11. Helium and Hydrogen Influence upon High-Temperature Ductility of 03Cr20Ni45Mo4NbBZr alloy. Radiation Effects Letters, 1984, N 85, p.33-36.

12. Helium and Hydrogen Influence upon High-Temperature Ductility of 16-15 steel and 20-45 nickel alloy - in Russian. Atomnaya energiya, 1986, v.60, is.1, p.61. 
13. Post-irradiation thermal processing effect upon helium embrittlement of OKh16N16M3B steel - in Russian...Physica metallov i metallovedeniye, 1993, v.75, no.6, p.147-149.

14. Study of structure of fast neutron irradiated at $300 \mathrm{C}$ stainless steel $\mathrm{Cr} 18 \mathrm{Ni} 40 \mathrm{Ti}$ in Russian. Atomnaya Energija, 1982, v.53, is.5, p.324.

15. Effect of Helium on Formation of Precipitates in $0 \mathrm{Cr} 16 \mathrm{Ni} 15 \mathrm{Mo} 3 \mathrm{Nb}$ Steel.Radiation Effects., 1986, vol.97, N 1-2, p.149.

16. Effect of Helium on Formation of Precipitates in 0Kh16N15M3B Steel - in Russian. Fizica i himiya obrabotki materialov, 1987, N.3, p.34-36.

17. Thermal stability of dislocation loops and fine particles formation in heliumdoped OKh16N15M3B steel - in Russian. Atomnaya Energiya, 1990, v.69, is.3, p.140-142.

18. The peculiarities of helium effect on the ageing of $0 \mathrm{Kh} 16 \mathrm{~N} 15 \mathrm{M} 3 \mathrm{~B}$ steel - in Russian. Atomnaya energiya, 1990, v.69, is.5, p.294-297.

19. Energy accumulation and microstructure transformation during deformation of 12Cr18Ni10Ti steel - in Russian. Metallophysica, 1991, v.13, N.10, p.36-40.

20. Dislocation loops annealing in helium-implanted OKh16N15M3B steel - in Russian. Fizica metallov i metallovedeniye, 1993, v.75, is.3, p.125-128.

21. The Annealing of Dislocation Loops in 0Kh16N15M3T Steel Implanted with Helium.- The Physics of Metals and Metallography, 1993, vol.75, N 3, pp.309311. 
22. Dislocation loops annealing kinetics in OKh16N15M3B steel with helium - in Russian. Izvestiya NAN RK, seriya fizico-matematicheskaya, 1993, N 2(171), p.19-23.

23. Radiation damage of helium implanted OKh16N15M3B steel - in Russian. Atomnaya energiya, 1993, v.74, is.5, p.444-446.

24. Double-function simulation of $14 \mathrm{MeV}$ neutron damage by alpha-particles - in Russian. Zhurnal experimentalnoy i teoreticheskoy fiziki, 1983, v.53, is.1.

25. Defect structure evolution in neon-doped zone in molybdenum during postirradiation annealing - in Russian. Preprint OIYaI (Dubna), 1983, N14-83-444.

26. Multi-purpose target device - in Russian. In "Modification of construction materials properties by charged particle beams", Tomsk, 1994, v.1, p.56. 


\section{APPENDIX 1}

Technical Staff.

\begin{tabular}{|c|c|c|c|}
\hline Name & $\begin{array}{l}\text { Area of project } \\
\text { expertise }\end{array}$ & $\begin{array}{l}\text { Scientific } \\
\text { rank }\end{array}$ & $\begin{array}{l}\text { Daily } \\
\text { rate }\end{array}$ \\
\hline Vagin S.P & Leader of the project & $\begin{array}{l}\text { Cand.phys. } \\
\text { math.sci. }\end{array}$ & 30 \\
\hline Utkelbayev B.D. & $\begin{array}{l}\text { Co-ordinator of } \\
\text { experimental jobs, } \\
\text { TEM-study }\end{array}$ & $\begin{array}{l}\text { Cand.phys } \\
\text { math.sci. }\end{array}$ & 25 \\
\hline Chakrov P.V. & $\begin{array}{l}\text { TEM-study, irradiation } \\
\text { of samples }\end{array}$ & - & 25 \\
\hline Loktionov A.A. & $\begin{array}{l}\text { Cyclotron and reactor } \\
\text { irradiation }\end{array}$ & $\begin{array}{l}\text { Cand.phys. } \\
\text { math.sci. }\end{array}$ & 20 \\
\hline Poltavtseva V.P. & $\begin{array}{l}\text { Mechanical tests, } \\
\text { irradiation of samples }\end{array}$ & $\begin{array}{l}\text { Cand.phys. } \\
\text { math.sci. }\end{array}$ & 20 \\
\hline Kospanov N.K. & $\begin{array}{l}\text { SEM-study, irradiation } \\
\text { of samples }\end{array}$ & - & 10 \\
\hline Pjatiletova N.A. & $\begin{array}{l}\text { Optical metallography, } \\
\text { preparation of specimens }\end{array}$ & - & 10 \\
\hline
\end{tabular}

Support Staff.

\begin{tabular}{lcll}
\hline Personnel & $\begin{array}{l}\text { Number of } \\
\text { persons }\end{array}$ & \multicolumn{1}{c}{$\begin{array}{c}\text { Area of project } \\
\text { expertise }\end{array}$} & $\begin{array}{l}\text { Daily } \\
\text { rate }\end{array}$ \\
\hline Engineer & 2 & $\begin{array}{l}\text { Development of cyclotron } \\
\text { and reactor irradiation } \\
\text { methods }\end{array}$ & 10 \\
Technician & 4 & $\begin{array}{l}\text { Cyclotron and reactor } \\
\text { irradiation } \\
\text { Preparation of TEM- and } \\
\text { SEM-objects }\end{array}$ & 5 \\
\hline Labsistant & 2 & 5 \\
\hline
\end{tabular}




\section{APPENDIX 2}

Destination, size and number of samples for implantation.

\begin{tabular}{llll}
\hline Destination & Size of samples & $\begin{array}{l}\text { Number of } \\
\text { samples per } \\
\text { irradiation }\end{array}$ & \multicolumn{2}{l}{$\begin{array}{l}\text { Implantation } \\
\text { rate, appm/hour }\end{array}$} & \\
\hline Study of structure & $\begin{array}{l}\text { Diameter of } 3 \mathrm{~mm} \\
\text { and thickness of } \\
0.2 \mathrm{~mm} \text { disks }\end{array}$ & 36 & 0.18 \\
\hline Mechanical tests & $\begin{array}{l}\text { Plates of } 40 \times 7 \times 0.2 \\
\mathrm{~mm}^{3} \text { size }\end{array}$ & 3 & \\
\hline
\end{tabular}

\section{APPENDIX 3}

Costs of irradiation jobs.

Irradiation facility

Cost

Isochronous cyclotron U-150 M

50 USD/hour

Heavy ion accelerator UKP 2-1

$20 \mathrm{USD} /$ hour

Nuclear reactor IGR

$4000 \mathrm{USD} /$ test 


\section{APPENDIX A}

Table 1a. Technical Schedule.

\begin{tabular}{cllll}
\hline Year & $\begin{array}{l}\text { First } \\
\text { Quarter }\end{array}$ & $\begin{array}{l}\text { Second } \\
\text { Quarter }\end{array}$ & $\begin{array}{l}\text { Third } \\
\text { Quarter }\end{array}$ & $\begin{array}{l}\text { Fourth } \\
\text { Quarter }\end{array}$ \\
\hline First & TASK A1 & TASK A2 & TASK A3 & TASK A3 \\
\hline \multirow{2}{*}{ Second } & TASK A3 & TASK A4 & TASK A5 & TASK A5 \\
\hline
\end{tabular}

Table 2a. Implantation parameters, number of samples and required cyclotron time.

\begin{tabular}{llll}
\hline $\begin{array}{l}\text { Gaseous impurity } \\
\text { concentration }\end{array}$ & $\begin{array}{l}\text { Irradiation } \\
\text { temperature, }{ }^{\circ} \mathrm{C}\end{array}$ & $\begin{array}{l}\text { Number of } \\
\text { samples }\end{array}$ & $\begin{array}{l}\text { Cyclotron } \\
\text { time, hours }\end{array}$ \\
\hline & & 1 \\
10 appm He & 16 & 7 \\
100 appm He & 16 & 15 \\
200 appm He & 16 & 36 \\
500 appm He & & 16 & 72 \\
1000 appm He & 100 & 16 & 327 \\
& & 16 & 1 \\
30 appm H & & 16 & 11 \\
300 appm H & 16 & 22 \\
600 appm H & 16 & 54 \\
1500 appm H & 16 & 108 \\
3000 appm H & & & \\
\hline
\end{tabular}


Table 3a. Financial information (First year).

BUDGET ITEM FIRST SECOND THIRD FOURTH TOTAL QUARTER QUARTER QUARTER QUARTER

PAYMENTS TO

PARTICIPANTS

: -Technical Staff

-Support Staff

4200

1500

PAYMENTS TO

PARTICIPANTS 5700

TOTAL

\section{0}

1500

4200

1500

4200

1500

16800

6000

5700

5700

5700

22800

\section{EQUIPMENT}

-Cyclotron

irradiation

16350

$-$

-

16350

-Microhardness-

$\begin{array}{lr}\text { meter } & 10000 \\ \text {-Computer, printer } 5800 & \end{array}$

$-$

-

10000

5800

EQUIPMENT

TOTAL

32150

-

-

32150

MATERIALS

-Abrasives

200

200

-Chemical reagents -

-Photo-materials

-Stationary

500

100

100

-

$-$

200

200

500

MATERIALS

TOTAL

100

1000

100

100

1300

TRAVELS

GOVERNMENT

TAXES

1710

1710

1710

1710

6840

OVERHEAD

3966

841

751

751

6309

TOTAL COST

43626

9251

8261

8261

69399 
Table 4a. Financial information (Second year).

BUDGET ITEM FIRST SECOND THIRD FOURTH TOTAL QUARTER QUARTER QUARTER QUARTER

\begin{tabular}{llllll}
\hline $\begin{array}{l}\text { PAYMENTS TO } \\
\text { PARTICIPANTS }\end{array}$ & & & & & \\
- Technical Staff & 4200 & 4200 & 4200 & 4200 & 16800 \\
-Support Staff & 1500 & 1500 & 1500 & 1500 & 6000 \\
\hline $\begin{array}{l}\text { PAYMENTS TO } \\
\text { PARTICIPANTS }\end{array}$ & 5700 & 5700 & 5700 & 5700 & 22800 \\
TOTAL & & & & & \\
\hline EQUIPMENT & - & - & - & - & - \\
\hline $\begin{array}{l}\text { EQUIPMENT } \\
\text { TOTAL }\end{array}$ & - & - & - & - & - \\
\hline $\begin{array}{l}\text { MATERIALS } \\
\text {-Abrasives }\end{array}$ & 200 & - & - & - & 200 \\
-Chemical reagents & 200 & - & - & - & 200 \\
-Stationary & 100 & 100 & 100 & 100 & 400 \\
$\begin{array}{l}\text { MATERIALS } \\
\text { TOTAL }\end{array}$ & 500 & 100 & 100 & 100 & 800 \\
\hline TRAVELS & 10000 & - & - & - & 10000 \\
\hline $\begin{array}{l}\text { GOVERNMENT } \\
\text { TAXES }\end{array}$ & 1710 & 1710 & 1710 & 1710 & 6840 \\
\hline \begin{tabular}{l} 
OVERHEAD \\
\hline
\end{tabular} & 1791 & 751 & 751 & 751 & 4044 \\
\hline \begin{tabular}{l} 
TOTAL COST \\
\hline
\end{tabular} & 19701 & 8261 & 8261 & 8261 & 44484 \\
\hline
\end{tabular}


Table 5a. Summary cost of EXPERIMENT A.

BUDGET ITEM

PAYMENTS TO

PARTICIPANTS

EQUIPMENT

MATERIALS

TRAVELS

GOVERNMENT TAXES

OVERHEAD

TOTAL COST
FIRST YEAR

SECOND YEAR TOTAL

22800

22800

45600
32150

$-$

1300

800

2100

10000

10000

6840

6840

13680

6309

4044

10353

32150

69399

44484

113883 


\section{APPENDIX B}

Table 1b. Technical Schedule.

\begin{tabular}{cllll}
\hline Year & $\begin{array}{l}\text { First } \\
\text { quarter }\end{array}$ & $\begin{array}{l}\text { Second } \\
\text { quarter }\end{array}$ & $\begin{array}{l}\text { Third } \\
\text { quarter }\end{array}$ & $\begin{array}{l}\text { Fourth } \\
\text { quarter }\end{array}$ \\
\hline First & TASK B1 & TASK B2 & TASK B3 & TASK B3 \\
\hline Second & TASK B4 & TASK B5 & - & - \\
\hline
\end{tabular}

Table $2 \mathrm{~b}$. Implantation parameters, number of samples and required cyclotron time.

Gaseous impurity concentration
Irradiation

temperature, ${ }^{\circ} \mathrm{C}$
Number of samples
Cyclotron time, hours

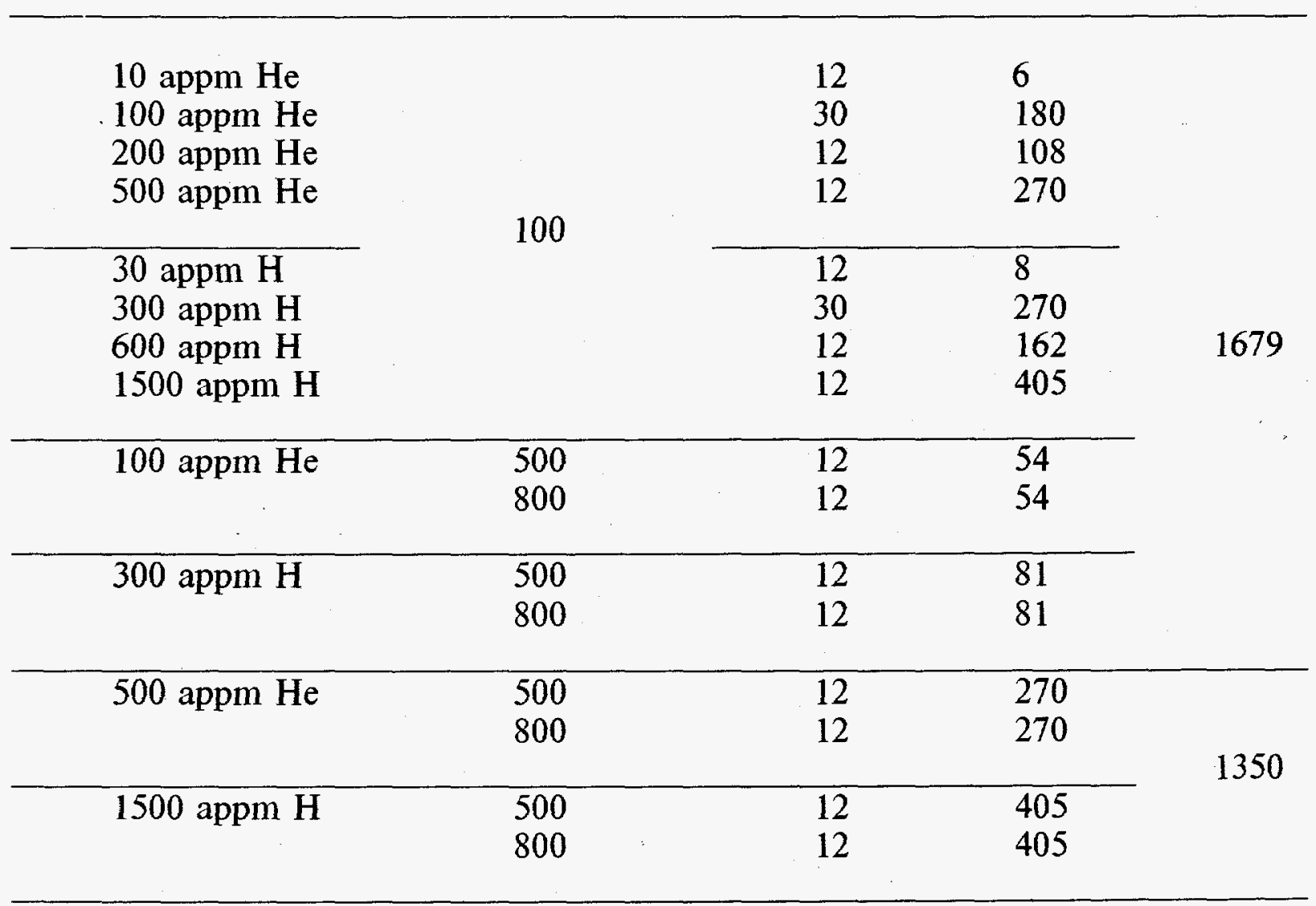


Table 3b. Financial information (First year).

\begin{tabular}{lllll}
\hline BUDGET ITEM & FIRST & SECOND & THIRD & FOURTH TOTAL \\
& QUARTER & QUARTER & QUARTER & QUARTER
\end{tabular}

\begin{tabular}{|c|c|c|c|c|c|}
\hline $\begin{array}{l}\text { PAYMENTS TO } \\
\text { PARTICIPANTS } \\
\text { 'Technical Staff } \\
\text {-Support Staff }\end{array}$ & $\begin{array}{l}4200 \\
1500\end{array}$ & $\begin{array}{l}4200 \\
1500\end{array}$ & $\begin{array}{l}4200 \\
1500\end{array}$ & $\begin{array}{l}4200 \\
1500\end{array}$ & $\begin{array}{l}16800 \\
6000\end{array}$ \\
\hline $\begin{array}{l}\text { PAYMENTS TO } \\
\text { PARTICIPANTS } \\
\text { TOTAL }\end{array}$ & 5700 & 5700 & 5700 & 5700 & 22800 \\
\hline $\begin{array}{l}\text { EQUIPMENT } \\
\text {-Cyclotron } \\
\text { irradiation } \\
\text {-Microhardness- } \\
\text { meter } \\
\text {-Computer, printer }\end{array}$ & $\begin{array}{r}83950 \\
10000 \\
5800\end{array}$ & $\begin{array}{l}67500 \\
- \\
-\end{array}$ & $\begin{array}{l}- \\
-\end{array}$ & $\begin{array}{l}- \\
-\end{array}$ & $\begin{array}{l}151450 \\
10000 \\
5800\end{array}$ \\
\hline $\begin{array}{l}\text { EQUIPMENT } \\
\text { TOTAL }\end{array}$ & 99750 & 67500 & - & - & 167250 \\
\hline $\begin{array}{l}\text { MATERIALS } \\
\text {-Chemical reagents } \\
\text {-Photo-materials } \\
\text {-Stationary }\end{array}$ & $\begin{array}{l}- \\
- \\
100\end{array}$ & $\begin{array}{l}- \\
- \\
100\end{array}$ & $\begin{array}{l}200 \\
500 \\
100\end{array}$ & $\begin{array}{l}- \\
- \\
100\end{array}$ & $\begin{array}{l}200 \\
500 \\
400\end{array}$ \\
\hline $\begin{array}{l}\text { MATERIALS } \\
\text { TOTAL }\end{array}$ & 100 & 100 & 800 & 100 & 1100 \\
\hline TRAVELS & - & - & - & - & - \\
\hline $\begin{array}{l}\text { GOVERNMENT } \\
\text { TAXES }\end{array}$ & 1710 & 1710 & 1710 & 1710 & 6840 \\
\hline$\overline{\text { OVERHEAD }}$ & 10726 & 7501 & 8221 & 751 & 19799 \\
\hline TOTAL COST & 117986 & 82511 & 9031 & 8261 & 217789 \\
\hline
\end{tabular}


Table 4b. Financial information (Second year).

\section{BUDGET ITEM FIRST SECOND THIRD FOURTH TOTAL QUARTER QUARTER QUARTER QUARTER}

\begin{tabular}{llllll}
\hline $\begin{array}{l}\text { PAYMENTS TO } \\
\text { PARTICIPANTS }\end{array}$ & & & & & \\
-Technical Staff & 4200 & 4200 & - & - & 8400 \\
-Support Staff & 1500 & 1500 & - & - & 3000 \\
\hline $\begin{array}{l}\text { PAYMENTS TO } \\
\text { PARTICIPANTS }\end{array}$ & 5700 & 5700 & - & - & 11400 \\
TOTAL & & & & & \\
\hline EQUIPMENT & - & - & - & - & - \\
\hline $\begin{array}{l}\text { EQUIPMENT } \\
\text { TOTAL }\end{array}$ & - & - & - & - & - \\
\hline $\begin{array}{l}\text { MATERIALS } \\
\text {-Photo-materials }\end{array}$ & 500 & - & - & - & 500 \\
-Stationary & 100 & 100 & - & - & 200 \\
\hline $\begin{array}{l}\text { MATERIALS } \\
\text { TOTAL }\end{array}$ & 600 & 100 & - & - & 700 \\
\hline TRAVELS & 10000 & - & - & - & 10000 \\
\hline $\begin{array}{l}\text { GOVERNMENT } \\
\text { TAXES }\end{array}$ & 1710 & 1710 & - & - & 3420 \\
\hline \begin{tabular}{l} 
OVERHEAD \\
\hline
\end{tabular} & 1801 & 751 & - & - & 2552 \\
\hline \begin{tabular}{l} 
TOTAL COST \\
\hline
\end{tabular} & 19811 & 8261 & - & - & 28072 \\
\hline
\end{tabular}


Table 5b. Summary cost of EXPERIMENT B.

\begin{tabular}{llll}
\hline BUDGET ITEM & FIRST YEAR & SECOND YEAR & TOTAL \\
\hline $\begin{array}{l}\text { PAYMENTS TO } \\
\text { PARTICIPANTS }\end{array}$ & 22800 & 11400 & 34200 \\
EQUIPMENT & 167250 & - & 167250 \\
MATERIALS & 1100 & 700 & 1800 \\
TRAVELS & - & 10000 & 10000 \\
GOVERNMENT TAXES & 6840 & 3420 & 10260 \\
OVERHEAD & 19799 & 2552 & 22351 \\
\hline TOTAL COST & 217789 & 28072 & 245861 \\
\hline
\end{tabular}




\section{APPENDIX C}

Table 1c. Technical Schedule.

\begin{tabular}{cllll}
\hline Year & $\begin{array}{l}\text { First } \\
\text { quarter }\end{array}$ & $\begin{array}{l}\text { Second } \\
\text { quarter }\end{array}$ & $\begin{array}{l}\text { Third } \\
\text { quarter }\end{array}$ & $\begin{array}{l}\text { Fourth } \\
\text { quarter }\end{array}$ \\
\hline First & TASK C1 & TASK C2 & TASK C3 & TASK C3 \\
\hline Second & TASK C4 & TASK C5 & TASK C5 & TASK C5 \\
\hline Third & TASK C6 & TASK C6 & TASK C7 & TASK C8 \\
\hline
\end{tabular}

Table 2c. Implantation parameters, number of samples and required cyclotron time.

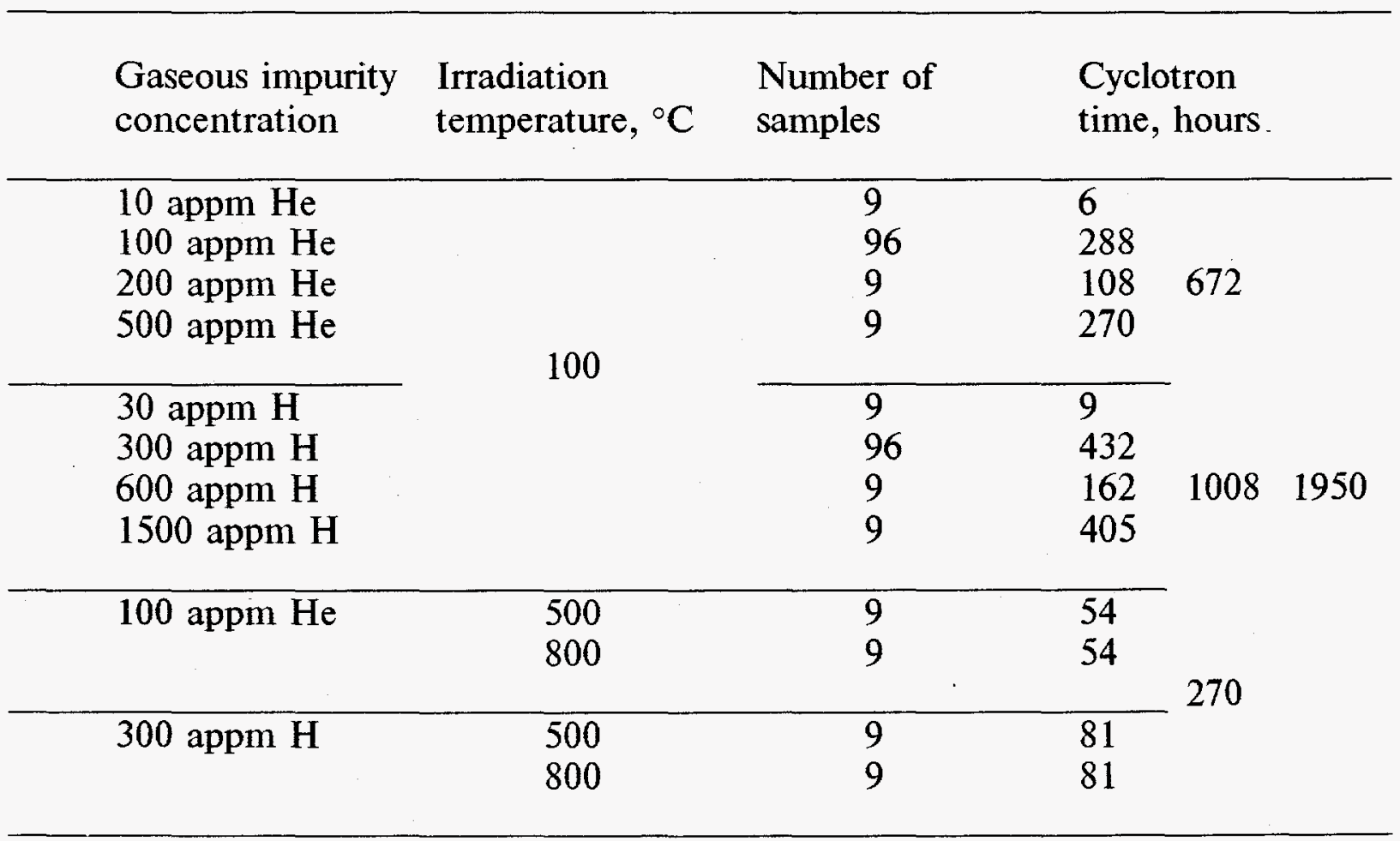


Table 3c. Concentration of helium and hydrogen atoms in samples for reactor irradiation, number of samples, neutron fluxes and number of reactor tests.

Concentration

of helium and

$1 \times 10^{16}$

Neutron flux, $\mathrm{n} / \mathrm{cm}^{2} \mathrm{~s}$

$5 \times 10^{16}$ $1 \times 10^{17}$

Number

hydrogen

100 appm $\mathrm{He}$ 300 appm $\mathrm{H}$

12

12

12

12

48

100 appm $\mathrm{He}+$

300 appm H

10 appm $\mathrm{He}$

30 appm $\mathrm{H}$

10 appm $\mathrm{He}+$

30 appm $\mathrm{H}$

200 appm $\mathrm{He}$

600 appm $\mathrm{H}$

200 appm $\mathrm{He}+$

600 appm $\mathrm{H}$

500 appm $\mathrm{He}$

1500 appm $\mathrm{H}$

500 appm $\mathrm{He}+$

1500 appm $H$

$\mathrm{T}_{\text {implan. }}=500^{\circ} \mathrm{C}$

100 appm $\mathrm{He}$

300 appm $\mathrm{H}$

100 appm $\mathrm{He}+$

300 appm H

$\mathrm{T}_{\text {implan. }}=800^{\circ} \mathrm{C}$

100 appm $\mathrm{He}$

300 appm H

100 appm $\mathrm{He}+$

300 appm $\mathrm{H}$ 
Table 4c. Financial information (First year).

$\begin{array}{lllll}\text { BUDGET ITEM } & \text { FIRST } & \text { SECOND } & \text { THIRD } & \text { FOURTH TOTAL }\end{array}$ QUARTER QUARTER QUARTER QUARTER

\begin{tabular}{|c|c|c|c|c|c|}
\hline $\begin{array}{l}\text { PAYMENTS TO } \\
\text { PARTICIPANTS } \\
\text {-Technical Staff } \\
\text {-Support Staff }\end{array}$ & $\begin{array}{l}4200 \\
1500\end{array}$ & $\begin{array}{l}4200 \\
1500\end{array}$ & $\begin{array}{l}4200 \\
1500\end{array}$ & $\begin{array}{l}4200 \\
1500\end{array}$ & $\begin{array}{l}16800 \\
6000\end{array}$ \\
\hline $\begin{array}{l}\text { PAYMENTS TO } \\
\text { PARTICIPANTS } \\
\text { TOTAL }\end{array}$ & 5700 & 5700 & 5700 & 5700 & 22800 \\
\hline $\begin{array}{l}\text { EQUIPMENT } \\
\text {-Cyclotron } \\
\text { irradiation } \\
\text {-Microhardness- } \\
\text { meter } \\
\text {-Computer, printer }\end{array}$ & $\begin{array}{l}500 \\
10000 \\
5800\end{array}$ & $\begin{array}{l}33600 \\
- \\
-\end{array}$ & $\begin{array}{l}63900 \\
- \\
-\end{array}$ & $\begin{array}{l}- \\
-\end{array}$ & $\begin{array}{l}98000 \\
10000 \\
5800\end{array}$ \\
\hline $\begin{array}{l}\text { EQUIPMENT } \\
\text { TOTAL }\end{array}$ & 16300 & 33600 & 63900 & - & 113800 \\
\hline $\begin{array}{l}\text { MATERIALS } \\
\text {-Abrasives } \\
\text {-Chemical reagents } \\
\text {-Photo-materials } \\
\text {-Stationary }\end{array}$ & $\begin{array}{l}200 \\
200 \\
500 \\
100\end{array}$ & $\begin{array}{l}- \\
- \\
- \\
100\end{array}$ & $\begin{array}{l}- \\
- \\
- \\
100\end{array}$ & $\begin{array}{l}- \\
- \\
- \\
100\end{array}$ & $\begin{array}{l}200 \\
200 \\
500 \\
400\end{array}$ \\
\hline $\begin{array}{l}\text { MATERIALS } \\
\text { TOTAL }\end{array}$ & 1000 & 100 & 100 & 100 & 1300 \\
\hline TRAVELS & - & - & - & - & - \\
\hline $\begin{array}{l}\text { GOVERNMENT } \\
\text { TAXES }\end{array}$ & 1710 & 1710 & 1710 & 1710 & 6840 \\
\hline OVERHEAD & 2471 & 4111 & 7141 & 751 & 14474 \\
\hline TOTAL COST & 27181 & 45221 & 78551 & 8261 & 159214 \\
\hline
\end{tabular}


Table 5c. Financial information (Second year).

$\begin{array}{lllll}\text { BUDGET ITEM } & \text { FIRST } & \text { SECOND } & \text { THIRD } & \text { FOURTH TOTAL } \\ & \text { QUARTER } & \text { QUARTER } & \text { QUARTER } & \text { QUARTER }\end{array}$

\begin{tabular}{|c|c|c|c|c|c|}
\hline $\begin{array}{l}\text { PAYMENTS TO } \\
\text { PARTICIPANTS } \\
\text {-Technical Staff } \\
\text {-Support Staff }\end{array}$ & $\begin{array}{l}4200 \\
1500\end{array}$ & $\begin{array}{l}4200 \\
1500\end{array}$ & $\begin{array}{l}4200 \\
1500\end{array}$ & $\begin{array}{l}4200 \\
1500\end{array}$ & $\begin{array}{l}16800 \\
6000\end{array}$ \\
\hline $\begin{array}{l}\text { PAYMENTS TO } \\
\text { PARTICIPANTS } \\
\text { TOTAL }\end{array}$ & 5700 & 5700 & 5700 & 5700 & 22800 \\
\hline $\begin{array}{l}\text { EQUIPMENT } \\
\text {-Reactor } \\
\text { irradiation }\end{array}$ & 96000 & 112000 & - & - & 208000 \\
\hline $\begin{array}{l}\text { EQUIPMENT } \\
\text { TOTAL }\end{array}$ & 96000 & 112000 & - & - & 208000 \\
\hline $\begin{array}{l}\text { MATERIALS } \\
\text {-Abrasives } \\
\text {-Chemical reagents } \\
\text {-Photo-materials } \\
\text {-Stationary }\end{array}$ & $\begin{array}{l}- \\
500 \\
100\end{array}$ & $\begin{array}{l}200 \\
200 \\
- \\
100\end{array}$ & $\begin{array}{l}- \\
- \\
- \\
100\end{array}$ & $\begin{array}{l}- \\
- \\
- \\
100\end{array}$ & $\begin{array}{l}200 \\
200 \\
500 \\
400\end{array}$ \\
\hline $\begin{array}{l}\text { MATERIALS } \\
\text { TOTAL }\end{array}$ & 600 & 500 & 100 & 100 & 1300 \\
\hline TRAVELS & - & - & 10000 & - & 10000 \\
\hline $\begin{array}{l}\text { GOVERNMENT } \\
\text { TAXES }\end{array}$ & 1710 & 1710 & 1710 & 1710 & 6840 \\
\hline OVERHEAD & 10401 & 11991 & 1751 & 751 & 24894 \\
\hline TOTAL COST & 114411 & 131901 & 19261 & 8261 & 273834 \\
\hline
\end{tabular}


Table 6c. Financial information (Third year).

\section{BUDGET ITEM FIRST SECOND THIRD FOURTH TOTAL QUARTER QUARTER QUARTER QUARTER}

PAYMENTS TO

PARTICIPANTS

- Technical Staff

-Support Staff

4200

1500

4200
1500

4200

1500

16800

6000

PAYMENTS TO

PARTICIPANTS 5700

5700

5700

5700

22800

\section{EQUIPMENT \\ EQUIPMENT \\ TOTAL \\ MATERIALS}

-Abrasives

200

-Chemical reagents 200

-Photo-materials 500

-Stationary

100

MATERIALS

TOTAL

1000

100

100

100

1300

TRAVELS

GOVERNMENT

TAXES

1710

1710

1710

1710

\begin{tabular}{llllll}
\hline OVERHEAD & 841 & 751 & 1751 & 751 & 4094 \\
\hline TOTAL COST & 9251 & 8261 & 19261 & 8261 & 45034
\end{tabular}

19261

8261

45034
200

200

500

400
TOTAL COST

9251

8261

6840

8261 
Table 5c. Summary cost of EXPERIMENT C.

\begin{tabular}{lllll}
\hline BUDGET ITEM & $\begin{array}{l}\text { FIRST } \\
\text { YEAR }\end{array}$ & $\begin{array}{l}\text { SECOND } \\
\text { YEAR }\end{array}$ & $\begin{array}{l}\text { THIRD } \\
\text { YEAR }\end{array}$ & TOTAL \\
\hline $\begin{array}{lllll}\text { PAYMENTS TO } \\
\text { PARTICIPANTS }\end{array}$ & 22800 & 22800 & 22800 & 68400 \\
EQUIPMENT & 113800 & 208000 & - & 321800 \\
MATERIALS & 1300 & 1300 & 1300 & 3900 \\
TRAVELS & - & 10000 & 10000 & 20000 \\
$\begin{array}{l}\text { GOVERNMENT } \\
\text { TAXES }\end{array}$ & 6840 & 6840 & 6840 & 20520 \\
OVERHEAD & 14474 & 24894 & 4094 & 43462 \\
\hline TOTAL COST & 159214 & 273834 & 45034 & 478082 \\
\hline
\end{tabular}




\section{APPENDIX D}

Table 1d. Technical Schedule.

\begin{tabular}{lllll}
\hline Year & $\begin{array}{l}\text { First } \\
\text { quarter }\end{array}$ & $\begin{array}{l}\text { Second } \\
\text { quarter }\end{array}$ & $\begin{array}{l}\text { Third } \\
\text { quarter }\end{array}$ & $\begin{array}{l}\text { Fourth } \\
\text { quarter }\end{array}$ \\
\hline First & TASK D1 & TASK D2 & TASK D3 & TASK D3 \\
\hline Second & TASK D4 & TASK D5 & TASK D5 & TASK D6 \\
\hline
\end{tabular}

Table 2d. Implantation parameters, number of samples and required cyclotron time.

\begin{tabular}{|c|c|c|c|c|}
\hline $\begin{array}{l}\text { Gaseous impurity } \\
\text { concentration }\end{array}$ & $\begin{array}{l}\text { Irradiation } \\
\text { temperature, }{ }^{\circ} \mathrm{C}\end{array}$ & $\begin{array}{l}\text { Number of } \\
\text { samples }\end{array}$ & & $\begin{array}{l}\text { Accelerator } \\
\text { time, hours }\end{array}$ \\
\hline $\begin{array}{l}10 \text { appm } \mathrm{He} \\
100 \text { appm He } \\
200 \text { appm } \mathrm{He} \\
500 \text { appm } \mathrm{He} \\
1000 \text { appm } \mathrm{He}\end{array}$ & \multirow{2}{*}{100} & $\begin{array}{l}36 \\
180 \\
36 \\
36 \\
36\end{array}$ & $\begin{array}{l}0,4 \\
20 \\
8 \\
20 \\
40\end{array}$ & \multirow{4}{*}{241} \\
\hline $\begin{array}{l}30 \text { appm H } \\
300 \text { appm } H \\
600 \text { appm } H \\
1500 \text { appm } H \\
3000 \text { appm } H\end{array}$ & & $\begin{array}{l}36 \\
180 \\
36 \\
36 \\
36\end{array}$ & $\begin{array}{l}0,6 \\
30 \\
12 \\
30 \\
60\end{array}$ & \\
\hline 100 appm He & $\begin{array}{l}500 \\
800\end{array}$ & $\begin{array}{l}36 \\
36\end{array}$ & $\begin{array}{l}4 \\
4\end{array}$ & \\
\hline 300 appm H & $\begin{array}{l}500 \\
800\end{array}$ & $\begin{array}{l}36 \\
36\end{array}$ & $\begin{array}{l}6 \\
6\end{array}$ & \\
\hline
\end{tabular}


Table 3d. Financial information (First year).

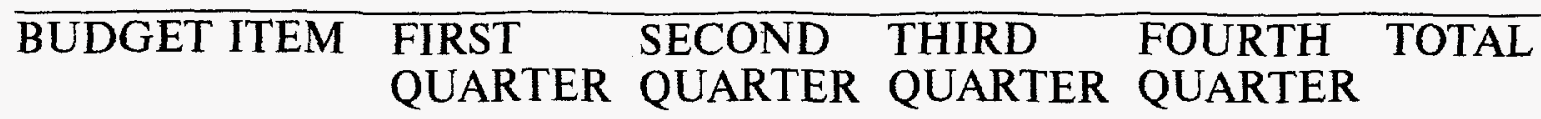

PAYMENTS TO

PARTICIPANTS

-Technical Staff

-Support Staff

4200

4200

4200

$4200 \quad 16800$

1500

1500

15006000

PAYMENTS TO

PARTICIPANTS

TOTAL

5700

5700

5700

$5700 \quad 22800$

EQUIPMENT

-Irradiation on UKP 2-1 4820

-Computer, printer

5800

$-$

4820

$\begin{array}{llll}- & - & - & 5800\end{array}$

EQUIPMENT TOTAL 10620

$-$

$-\quad-\quad 10620$

MATERIALS

-Chemical reagents

-Photo-materials

-Stationary

200

500

100

$-$

$-200$

$-$

100

$-\quad 500$

$100 \quad 400$

MATERIALS TOTAL

800

100

$100 \quad 1100$

TRAVELS

GOVERNMENT

TAXES

1710

1710

1710

$1710 \quad 6840$

OVERHEAD

1883

751

751

$751 \quad 4136$

TOTAL COST

20713

8261

8261

826145496 
Table 4d. Financial information (Second year).

$\begin{array}{lllll}\text { BUDGET ITEM } & \text { FIRST } & \text { SECOND } & \text { THIRD } & \text { FOURTH TOTAL } \\ & \text { QUARTER } & \text { QUARTER } & \text { QUARTER } & \text { QUARTER }\end{array}$

PAYMENTS TO

PARTICIPANTS

; - Technical Staff

-Support Staff

4200

4200

4200

4200

16800

1500

1500

1500

6000

PAYMENTS TO

PARTICIPANTS

TOTAL

5700

5700

5700

22800

EQUIPMENT -

EQUIPMENT

TOTAL

MATERIALS

-Chemical reagents 200

-Photo-materials 500

-Stationary

100

$\begin{array}{ll}- & - \\ - & - \\ 100 & 100\end{array}$

$\begin{array}{ll}- & 200 \\ - & 500 \\ 100 & 400\end{array}$

MATERIALS

TOTAL 800

100

100

100

1100

TRAVELS -

$-$

$-$

10000

10000

GOVERNMENT

TAXES

1710

1710

1710

1710

6840

OVERHEAD

821

751

1751

751

4074

TOTAL COST 9031

8261

19261

8261

44814 
Table 5d. Summary cost of EXPERIMENT D.

\begin{tabular}{lccc}
\hline BUDGET ITEM & FIRST YEAR & SECOND YEAR & TOTAL \\
\hline PAYMENTS TO & 22800 & 22800 & 45600 \\
PARTICIPANTS & 10620 & - & 10620 \\
EQUIPMENT & 1100 & 1100 & 2200 \\
MATERIALS & - & 10000 & 10000 \\
TRAVELS & 6840 & 6840 & 13680 \\
GOVERNMENT & 4136 & 4074 & 8210 \\
TAXES & 45496 & 44814 & 90310 \\
OVERHEAD & & & \\
\hline TOTAL COST & &
\end{tabular}




\section{APPENDIX E}

Table 1e. Technical Schedule.

\begin{tabular}{lllll}
\hline Year & $\begin{array}{l}\text { First } \\
\text { quarter }\end{array}$ & $\begin{array}{l}\text { Second } \\
\text { quarter }\end{array}$ & $\begin{array}{l}\text { Third } \\
\text { quarter }\end{array}$ & $\begin{array}{l}\text { Fourth } \\
\text { quarter }\end{array}$ \\
\hline First & TASK E1 & TASK E2 & TASK E3 & TASK E4 \\
\hline Second & TASK E4 & TASK E5 & TASK E6 & TASK E5 \\
\hline
\end{tabular}

Table 2e. Implantation parameters, number of samples and required irradiation time.

$\begin{array}{llll}\begin{array}{l}\text { Gaseous impurity } \\ \text { concentration }\end{array} & \begin{array}{l}\text { Irradiation } \\ \text { temperature, }{ }^{\circ} \mathrm{C}\end{array} & \begin{array}{l}\text { Number of } \\ \text { samples }\end{array} & \begin{array}{l}\text { Accelerator } \\ \text { time, hours }\end{array}\end{array}$

\begin{tabular}{lllll}
\hline 10 appm He & & 36 & 0.4 & \\
100 appm He & & 36 & 4 & 44.4 \\
1000 appm He & 36 & 40 & \\
& 100 & & & \\
30 appm H & & 36 & 0.6 & \\
300 appm H & & 36 & 5.4 & 60 \\
300 appm H & 36 & 54 & \\
\hline
\end{tabular}

Table 3e. Proton irradiation parameters.

\begin{tabular}{cccll}
\hline $\begin{array}{l}\text { Irradiation } \\
\text { temperature, }{ }^{\circ} \mathrm{C}\end{array}$ & $\begin{array}{l}\text { Radiation } \\
\text { damage, dpa }\end{array}$ & $\begin{array}{l}\text { Number of } \\
\text { samples }\end{array}$ & $\begin{array}{l}\text { Accelerator } \\
\text { time, hours }\end{array}$ \\
\hline \multirow{2}{*}{500} & 1 & 36 & 4 & \\
& 5 & 36 & 20 & 174 \\
& 30 & 36 & 150 & \\
3 & 1 & 36 & 4 & \\
& 5 & 36 & 20 & 174 \\
& 30 & 36 & 150 & \\
\hline
\end{tabular}


Table 4e. Financial information (First year).

\begin{tabular}{lllll}
\hline BUDGET ITEM & FIRST & SECOND & THIRD & FOURTH TOTAL \\
& QUARTER & QUARTER & QUARTER & QUARTER
\end{tabular}

PAYMENTS TO

PARTICIPANTS

-Technical Staff

4200

4200

4200

4200

16800

-Support Staff

1500

1500

1500

1500

6000

PAYMENTS TO

PARTICIPANTS

TOTAL

5700

5700

5700

5700

22800

EQUIPMENT

-Implantation of 2088 gaseous impurities

-Proton irradiation 960

-Computer, printer 5800

$-$

2088

6000

$-$

6960

$-$

5800

EQUIPMENT

TOTAL

8848

6000

14848

MATERIALS

-Chemical reagents 200

-Photo-materials 500

-Stationary

100

-

200

-

100

100

-
$-\quad 500$
100

100

400

MATERIALS

TOTAL 800

$800 \quad 100$

100

100

1100

TRAVELS

GOVERNMENT

TAXES

1710

1710

1710

1710

6840

OVERHEAD

1705

1351

751

751

4558

TOTAL COST

18763

14861

8261

8261

50146 
Table 5e. Financial information (Second year).

\section{BUDGET ITEM FIRST SECOND THIRD FOURTH TOTAL QUARTER QUARTER QUARTER QUARTER}

\begin{tabular}{|c|c|c|c|c|c|}
\hline $\begin{array}{l}\text { PAYMENTS TO } \\
\text { PARTICIPANTS } \\
\text { - -Technical Staff } \\
\text {-Support Staff }\end{array}$ & $\begin{array}{l}4200 \\
1500\end{array}$ & $\begin{array}{l}4200 \\
1500\end{array}$ & $\begin{array}{l}4200 \\
1500\end{array}$ & $\begin{array}{l}4200 \\
1500\end{array}$ & $\begin{array}{l}16800 \\
6000\end{array}$ \\
\hline $\begin{array}{l}\text { PAYMENTS TO } \\
\text { PARTICIPANTS } \\
\text { TOTAL }\end{array}$ & 5700 & 5700 & 5700 & 5700 & 22800 \\
\hline EQUIPMENT & - & - & - & - & - \\
\hline $\begin{array}{l}\text { EQUIPMENT } \\
\text { TOTAL }\end{array}$ & - & - & - & - & - \\
\hline $\begin{array}{l}\text { MATERIALS } \\
\text {-Chemical reagents } \\
\text {-Photo-materials } \\
\text {-Stationary }\end{array}$ & $\begin{array}{l}200 \\
500 \\
100\end{array}$ & $\begin{array}{l}- \\
- \\
100\end{array}$ & $\begin{array}{l}- \\
- \\
100\end{array}$ & $\begin{array}{l}- \\
- \\
100\end{array}$ & $\begin{array}{l}200 \\
500 \\
400\end{array}$ \\
\hline $\begin{array}{l}\text { MATERIALS } \\
\text { TOTAL }\end{array}$ & 800 & 100 & 100 & 100 & 1100 \\
\hline TRAVELS & - & - & 10000 & - & 10000 \\
\hline $\begin{array}{l}\text { GOVERNMENT } \\
\text { TAXES }\end{array}$ & 1710 & 1710 & 1710 & 1710 & 6840 \\
\hline OVERHEAD & 821 & 751 & 1751 & 751 & 4074 \\
\hline TOTAL COST & 9031 & 8261 & 19261 & 8261 & 44814 \\
\hline
\end{tabular}


Table 6e. Summary cost of EXPERIMENT E.

\begin{tabular}{lccc}
\hline BUDGET ITEM & FIRST YEAR & SECOND YEAR & TOTAL \\
\hline $\begin{array}{l}\text { PAYMENTS TO } \\
\text { PARTICIPANTS }\end{array}$ & 22800 & 22800 & 45600 \\
EQUIPMENT & 14848 & - & 14848 \\
MATERIALS & 1100 & 1100 & 2200 \\
TRAVELS & - & 10000 & 10000 \\
GOVERNMENT & 6840 & 6840 & 13680 \\
TAXES & 4558 & 4074 & 8632 \\
OVERHEAD & 50146 & 44814 & 94960 \\
\hline TOTAL COST & & & \\
\hline
\end{tabular}

